\title{
Valorization of Wine-Making By-Products' Extracts in Cosmetics
}

\author{
Israa Hoss ${ }^{1,+}$, Hiba N. Rajha ${ }^{1,2, *,+} \mathbb{D}$, Rindala El Khoury ${ }^{1}$, Sahar Youssef ${ }^{1}$, Maria Letizia Manca ${ }^{3} \mathbb{D}$, \\ Maria Manconi ${ }^{3}$ (D), Nicolas Louka ${ }^{1}$ and Richard G. Maroun ${ }^{1}$ (D)
}

1 Centre d'Analyses et de Recherche, Unité de Recherche Technologies et Valorisations Agro-Alimentaire, Faculté des Sciences, Université Saint-Joseph de Beyrouth, P.O. Box 17-5208 Riad El Solh, Beirut 1104 2020, Lebanon; israa.hoss@net.usj.edu.lb (I.H.); rindala.khoury@net.usj.edu.lb (R.E.K.); sahar.youssef@tamerholding.com (S.Y.); nicolas.louka@usj.edu.lb (N.L.); richard.maroun@usj.edu.lb (R.G.M.)

2 Ecole Supérieure d'Ingénieurs de Beyrouth (ESIB), Université Saint-Joseph de Beyrouth, CST Mkalles Mar Roukos, Riad El Solh, Beirut 1107 2050, Lebanon

3 Centre for Nanobiotechnology Sardinia CNBS, Department of Scienze Della Vita e Dell'Ambiente, University of Cagliari, 09124 Cagliari, Italy; mlmanca@unica.it (M.L.M.); manconi@unica.it (M.M.)

* Correspondence: hiba.rajha@usj.edu.lb; Tel.: +961-78-821-568

+ Both authors equally contributed.

check for updates

Citation: Hoss, I.; Rajha, H.N.; El Khoury, R.; Youssef, S.; Manca, M.L.; Manconi, M.; Louka, N.; Maroun, R.G. Valorization of Wine-Making By-Products' Extracts in Cosmetics. Cosmetics 2021, 8, 109. https:// doi.org/10.3390/cosmetics8040109

Academic Editor: Piera Di Martino

Received: 20 October 2021

Accepted: 16 November 2021

Published: 18 November 2021

Publisher's Note: MDPI stays neutral with regard to jurisdictional claims in published maps and institutional affiliations.

Copyright: (C) 2021 by the authors Licensee MDPI, Basel, Switzerland. This article is an open access article distributed under the terms and conditions of the Creative Commons Attribution (CC BY) license (https:/ / creativecommons.org/licenses/by/ $4.0 /)$.
Abstract: The increased demand for conscious, sustainable and beneficial products by the consumers has pushed researchers from both industries and universities worldwide to search for smart strategies capable of reducing the environmental footprint, especially the ones connected with industrial wastes. Among various by-products, generally considered as waste, those obtained by winemaking industries have attracted the attention of a wide variety of companies, other than the vineries. In particular, grape pomaces are considered of interest due to their high content in bioactive molecules, especially phenolic compounds. The latter can be recovered from grape pomace and used as active ingredients in easily marketable cosmetic products. Indeed, phenolic compounds are well known for their remarkable beneficial properties at the skin level, such as antioxidant, antiaging, antihyperpigmentation and photoprotective effects. The exploitation of the bioactives contained in grape pomaces to obtain high value cosmetics may support the growing of innovative start-ups and expand the value chain of grapes. This review aims to describe the strategies for recovery of polyphenols from grape pomace, to highlight the beneficial potential of these extracts, both in vitro and in vivo, and their potential utilization as active ingredients in cosmetic products.

Keywords: cosmetics; grape pomace; phenolic compounds; antioxidants; extracts; natural active ingredient; sustainable development

\section{Introduction}

Valuable phenolic compounds can be recovered from several edible fruits and vegetables, but also from different food by-products such as citrus fruits, orange peels [1-3], lemon peels, pomelo peels [3], grapefruit peels [4] and olive leaves [5-7]. in addition to pomegranate fruits peels and seeds [8-10], peach pomace [11] and viticulture byproducts, in particular vine shoots [12-17] and winemaking by-products, especially grape pomace [18-22].

Grape by-products derived from the winery wastes consist mainly of vine stems, grape pomace and wine lees. Grape pomace is one of the most important residues, constituting between 20 and $25 \%$ of the initial grapes' weight and composed of $25 \%$ seeds, $25 \%$ stalks and $50 \%$ skins $[23,24]$. Grape pomace is generated during the winemaking process, after the fermentation step in the case of red grapes, and prior to it in the case of white grapes (Figure 1) [25]. Considering that 35.9 million tons of grapes are pressed yearly worldwide to produce wine [26], a large amount of such by-products is generated in a limited period of time causing ecological problems. In fact, polyphenols have a potential to alter the 
equilibrium of the ecosystem, by modifying organic compound pathways and the nutrients cycle [27].

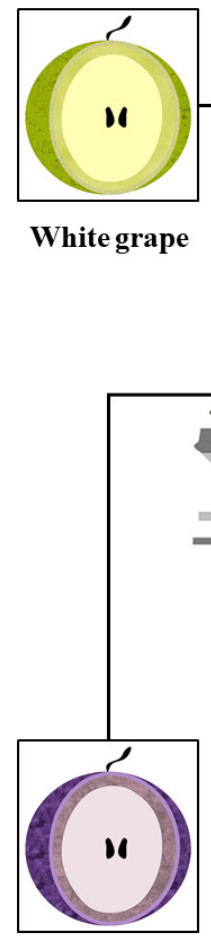

Red grape

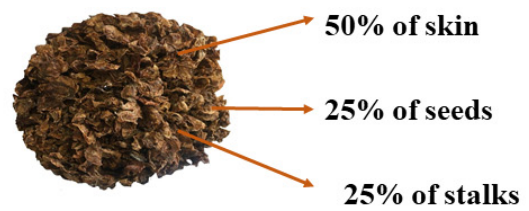

White grape pomace

\section{White grape pomace}
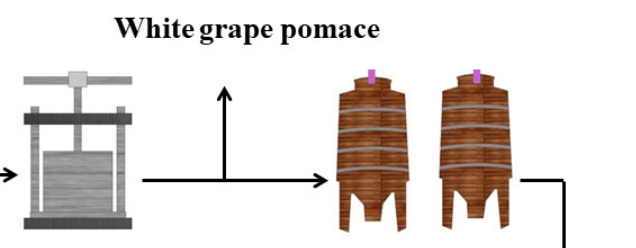

Pressing Fermentation

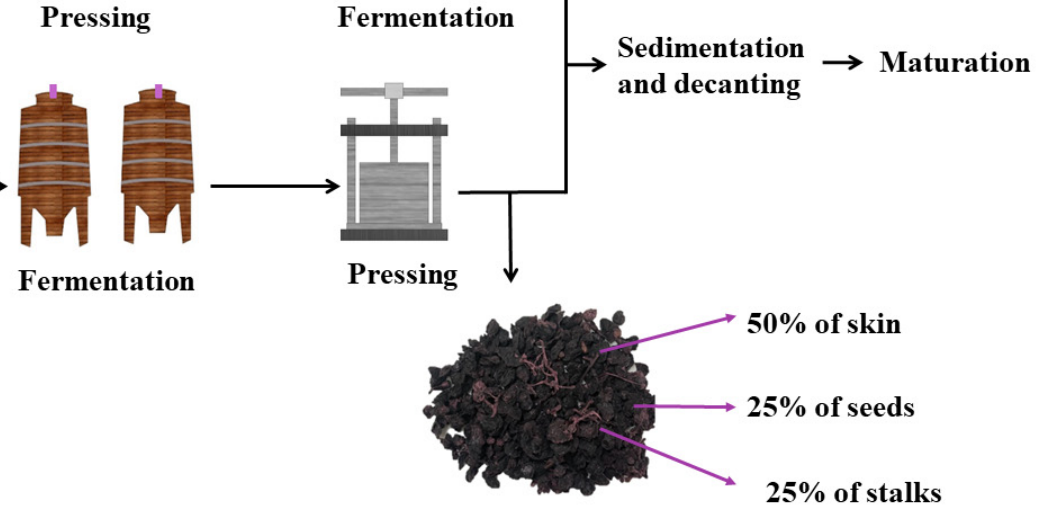

Red grape pomace

Figure 1. Grape pomace derived from the wine making process.

Given that, its exploitation and valorization by means of phenolic compounds' extraction is an attractive strategy aiming to recover functional compounds and, at the same time improve the lifecycle of grape production and use by reducing the environmental impact of its by-products [28]. Although considered as a waste, grape pomace still contains a high amount of valuable phenolic compounds. Those are characterized by the presence of at least one benzene ring with one or more hydroxyl substituents in their chemical structure [29].

Phenolic compounds can be divided into different groups: phenolic acids, flavonoids, tannins, lignans and neolignanes, stilbenes, coumarins and phenyl ethanol derivatives, (Figure 2) [30]. These molecules are naturally produced by the majority of plants as a strategy to protect and defend themselves against environmental aggressions and pathogens such as bacteria, fungi, etc. [31]. At the same time, and when properly used, these secondary metabolites may exert beneficial and protective activities for the human body. Indeed, they can be used as active ingredients in pharmaceutical, food and cosmetic products [32-35].

The aim of this work is to examine the extraction methods used for the recovery of bioactive polyphenols and their effective potential as functional ingredient in cosmetic applications. The novelty of this review resides in its waste-to-market approach. It analyses the effects of the extraction methods and parameters on the diversity and quality of the recovered phenolic compounds and their stability when incorporated in cosmetic products. The activity of the extracts studied in vitro, and/or incorporated in cosmetic products and evaluated in vitro and/or in vivo was also presented. The purpose of the review is to give a wide view of the life cycle of Vitis vinifera by-products starting by the extraction process of phenolic compounds and their characterization, passing through their in vitro study to finally reach the cosmetic application and the in vivo validation in clinical trials (Figure 3). 


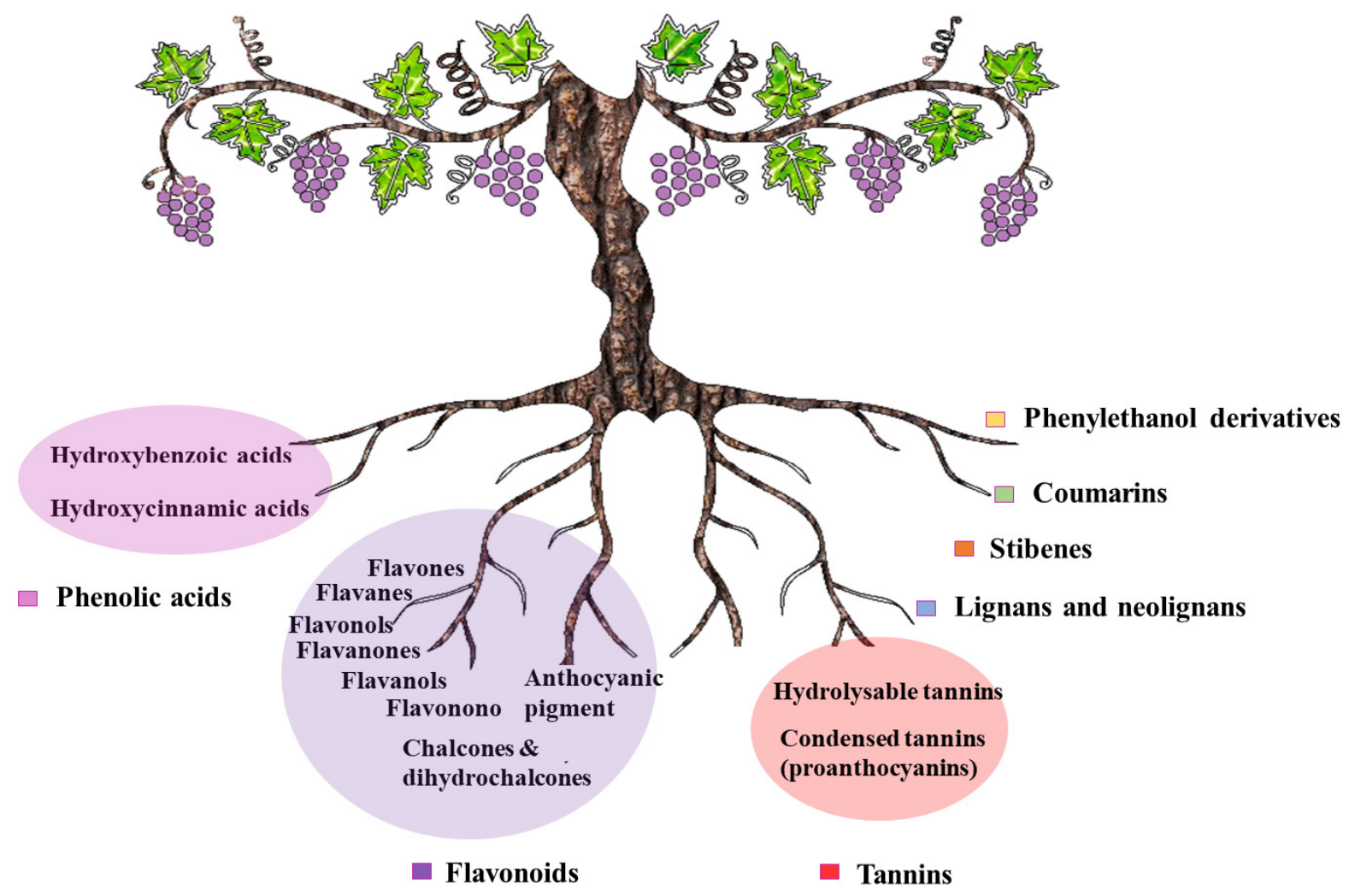

Figure 2. Schematic representation of phenolic compounds' groups.

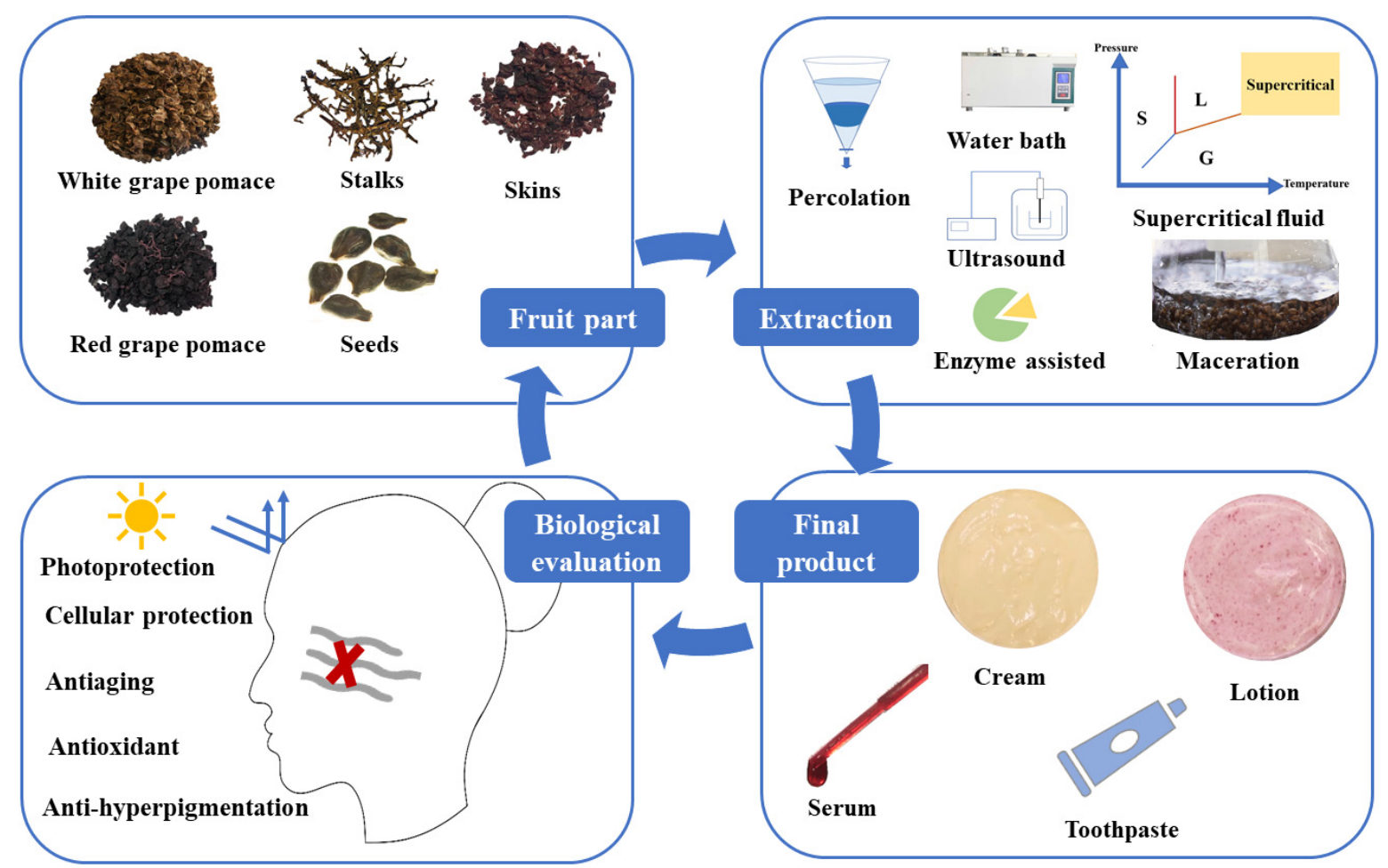

Figure 3. Schematic representation of the life cycle of Vitis vinifera, starting by the studied by-product, then the extraction technique, the cosmetics products in which polyphenols were formulated and finally the acquired biological activities. 


\section{Extraction of Phenolic Compounds from Grape By-Products}

The extraction process is the first key step towards the recovery of phenolic compounds. The effectiveness of the process relies on the matrices used, the experimental conditions, the type of phenolic compounds to be extracted and the applied method [36]. Aiming to improve the extraction efficacy of polyphenols from grape by-products, different treatment techniques, extraction parameters and solvents have been used and several combinations of polyphenols were recovered. Table 1 gathers data about the extraction methods, parameters and solvents used for the different studied activities of the grape by-products' extracts used in cosmetics.

The overall reported procedure of the obtainment of functional ingredients from grape by-products consisted of an optional pre-treatment step (e.g., grinding), followed by an extraction process (e.g., ultrasound), a separation and concentration step (rotary evaporation), and finally a dehydration step (e.g., freeze drying).

The majority of the pre-treatment of the grape by-products consist of grinding. This mechanical reduction of particle size improves the extraction rate by reducing the distance the solute has to diffuse from the solid to the solvent [19].

Some innovative technologies such as microwave irradiation can be used in both pre-treatment or treatment processes. Matos et al. suggested that a short (60 s) microwave irradiation pre-treatment $\left(80^{\circ} \mathrm{C}\right)$ of the grape pomace led to targeting an enhanced selective extraction of anthocyanins compared to untreated samples. In fact, microwaves allow rapid heating of water molecules in the grape pomace, thus accelerating the extraction of the valuable compounds [37].

Besides the role of pre-treatments, like grinding or microwaves, in enhancing the recovery of phenolic compounds from the matrices, they are also used to eliminate undesired compounds. For example, in order to avoid the stickiness of the grape skin extract during freeze drying, it was pre-treated by suspending it in water for $24 \mathrm{~h}$ at $25^{\circ} \mathrm{C}$ to reduce its sugar content [38].

After the pre-treatment process, many extraction methods are used to recover phenolic compounds from grape by-products. For example, ultrasound [39,40], supercritical fluid [40], maceration [22,41-43], enzyme-assisted extraction [44], percolation [45] and traditional solid liquid extraction [37-39,46,47] are mentioned. Solid liquid extraction remains the most commonly used and accessible technique in the studies of polyphenol extraction for application in cosmetic products.

The majority of the extraction processes were performed by using organic solvents, in particular ethanol and water blends. Indeed hydroethanolic mixture solvents facilitate the solubility of the phenolic compounds and enhance their extraction [38]. Maluf et al. compared the efficiency of polyphenol extraction from Vitis labrusca L. pomace using different solvent mixtures. Acetone:water $(75: 25)$ provided the highest yield $\left(190 \mathrm{mg} \cdot \mathrm{g}^{-1}\right)$ of polyphenols, compared to methanol:water $\left(75: 25,100 \mathrm{mg} \cdot \mathrm{g}^{-1}\right)$, acetone $\left(100 \%, 90 \mathrm{mg} \cdot \mathrm{g}^{-1}\right)$, ethanol $(100 \%$, $\left.50 \mathrm{mg} \cdot \mathrm{g}^{-1}\right)$, ethanol:water $\left(75: 25,20 \mathrm{mg} \cdot \mathrm{g}^{-1}\right)$, and methanol $\left(100 \%, 20 \mathrm{mg}^{-1} \mathrm{~g}^{-1}\right)$ [47].

Recently, the user-friendly COSMOtherm tool was suggested to design tailor-made GREEN and GRAS deep eutectic solvents. The latter can be used for an environmentally friendly recovery of polyphenols from grape pomaces to be used in subsequent cosmetic applications. This software is expected to save time and reduce the experimental costs of the solvent selection process [48].

After the extraction process, the exhausted solid pomace is mainly separated from the liquid extract by filtration or centrifugation and the organic solvent is then mainly regenerated by rotary evaporation. The concentrated aqueous remaining extract is either used as it is in cosmetic applications or transformed into a powder by freeze drying (Table 1).

The majority of studies have used spectrophotometry (Folin-Ciocalteu) and/or chromatography (HPLC) to identify and quantify the main phenolic compounds. The main components detected in grape pomaces by HPLC were gallic acid, catechin, epicatechin and quercetin (Table 1). Moreover, this identification was sometimes linked to the skin 
biological activity. For example, quercetin and gallic acid have the highest capacity to inhibit the tyrosinase activity and are therefore expected to decrease the hyperpigmentation activity in human skin [44]. The ultimate goal of Table 1 is to link the extraction techniques to the quality (selectivity, polarity, etc.) and quantity of the obtained polyphenols and subsequently to their biological activities on the skin.

Some papers analyzed only the in vitro biological activities of the crude grape pomace extracts $[22,37,38,40,44,46,47]$ (Table 2). Meanwhile others incorporated those extracts (liquid or powder) into cosmetic products and studied their in vitro [39,41,42,45,49,50] and/or in vivo effects $[39,43,45,51]$ (Table 3 ). 
Table 1. Grape variety, pre-treatment, extraction parameters, extract treatment, analytical methods and identified compounds for the corresponding studied activities in cosmetics.

\begin{tabular}{|c|c|c|c|c|c|c|c|c|c|c|c|}
\hline \multirow{2}{*}{$\begin{array}{c}\text { Grape } \\
\text { Variety/Fruit } \\
\text { Part }\end{array}$} & \multirow[t]{2}{*}{$\begin{array}{c}\text { Pre- } \\
\text { Treatment }\end{array}$} & \multirow{2}{*}{$\begin{array}{l}\text { Extraction Parameters } \\
\text { (Method; Solvent; } \\
\text { Solid to Liquid Ratio; } \\
\text { Time; Temperature) }\end{array}$} & \multirow[t]{2}{*}{$\begin{array}{l}\text { Extract } \\
\text { Treatment }\end{array}$} & \multirow[t]{2}{*}{$\begin{array}{l}\text { Spectrophotometric } \\
\text { Methods }\end{array}$} & \multirow[t]{2}{*}{$\begin{array}{l}\text { Chromatographic } \\
\text { Methods }\end{array}$} & \multirow[t]{2}{*}{$\begin{array}{l}\text { Identified Phenolic } \\
\text { Compounds }\end{array}$} & \multirow{2}{*}{$\begin{array}{l}\text { Analysis } \\
\text { on Extract } \\
\text { In Vitro }\end{array}$} & \multicolumn{2}{|c|}{$\begin{array}{c}\text { Incorporation in } \\
\text { Product }\end{array}$} & \multirow[t]{2}{*}{$\begin{array}{l}\text { Studied } \\
\text { Activity }\end{array}$} & \multirow[t]{2}{*}{ Ref } \\
\hline & & & & & & & & In Vitro & In Vivo & & \\
\hline $\begin{array}{c}\text { Vitis } \\
\text { viniferaL./seeds }\end{array}$ & Drying & $\begin{array}{c}\text { Solid liquid extraction } \\
\text { EtOH: } \mathrm{H}_{2} \mathrm{O}(95: 5 v / v) \\
7 \text { days }\end{array}$ & $\begin{array}{l}\text { Concentration } \\
\text { under rotavapor } \\
\left(40^{\circ} \mathrm{C}\right) \\
\text { Filtration }\end{array}$ & $\begin{array}{l}\text { DPPH and FRAP } \\
\text { assays }\end{array}$ & HPLC & $\begin{array}{l}\text { Catechin, epicatechin, gallic } \\
\text { acid, epicatechin gallate, and } \\
\text { procyanidin } \\
\text { dimers (B-1, B-2 and B-3) }\end{array}$ & Yes & No & Yes & Antiaging & [49] \\
\hline \multirow{2}{*}{$\begin{array}{l}\text { Vitis viniferaL. } \\
\text { Grechetto/skin } \\
\text { and seeds }\end{array}$} & - & $\begin{array}{c}\text { Homogenizing by } \\
\text { UltraTurrax T25 (3 min, } \\
30,618 \text { g) or ultrasound } \\
\text { bath }(5 \text { min) } \\
\text { EtOH: } \mathrm{H}_{2} \mathrm{O}(60: 40 \mathrm{v} / \mathrm{v}) \\
\text { or } \mathrm{H}_{2} \mathrm{O}(100 \%) \\
1: 2\end{array}$ & $\begin{array}{l}\text { Centrifugation } \\
(21,074 \times g \\
\left.15 \mathrm{~min}, 4^{\circ} \mathrm{C}\right)\end{array}$ & \multirow{2}{*}{$\begin{array}{l}\text { Proanthocyanidins, } \\
\text { Folin-Ciocalteu } \\
\text { and DPPH assays }\end{array}$} & \multirow{2}{*}{$\begin{array}{c}\text { Reversed } \\
\text { phase-HPLC }\end{array}$} & \multirow{2}{*}{ Quercetin glucoside } & \multirow{2}{*}{ No } & \multirow{2}{*}{ Yes } & \multirow{2}{*}{ No } & \multirow{3}{*}{ Antioxidant } & \multirow{3}{*}{ [39] } \\
\hline & $\begin{array}{l}\text { Freezing } \\
\text { under liquid } \\
\text { nitrogen } \\
\text { Grinding }\end{array}$ & $\begin{array}{c}\text { Solid liquid extraction } \\
\text { EtOH (100\%) } \\
1: 3 \\
1 \mathrm{~h} \\
20^{\circ} \mathrm{C}\end{array}$ & $\begin{array}{c}\text { Centrifugation } \\
(21,074 \times g, \\
\left.15 \text { min, } 4^{\circ} \mathrm{C}\right) \\
\text { Concentration } \\
\text { under rotavapor } \\
\left(4^{\circ} \mathrm{C}\right) \\
\text { Freeze drying }\end{array}$ & & & & & & & & \\
\hline $\begin{array}{l}\text { Vitis vinifera L. } \\
\text { Cabernet } \\
\text { Sauvi- } \\
\text { gnon/seeds }\end{array}$ & $\begin{array}{l}\text { Freezing } \\
\text { under liquid } \\
\text { nitrogen } \\
\text { Grinding }\end{array}$ & $\begin{array}{c}\text { Solid liquid extraction } \\
\text { EtOH: } \mathrm{H}_{2} \mathrm{O}(60: 40 v / v) \\
\text { or } \mathrm{H}_{2} \mathrm{O}(100 \%) \\
1: 10 \\
1 \mathrm{~h} \\
20^{\circ} \mathrm{C}\end{array}$ & $\begin{array}{c}\text { Centrifugation } \\
(21,074 \times g, \\
\left.15 \text { min, } 4^{\circ} \mathrm{C}\right) \\
\text { Concentration } \\
\text { under rotavapor } \\
\left(4^{\circ} \mathrm{C}\right) \\
\text { Freeze drying }\end{array}$ & $\begin{array}{c}\text { Folin-Ciocalteu } \\
\text { assay }\end{array}$ & - & - & No & Yes & Yes & & \\
\hline Carignano/skins & $\begin{array}{l}\text { Freeze drying } \\
\text { Grinding } \\
\text { Suspension in } \\
\text { distilled water } \\
\text { (constant } \\
\text { stirring, } 24 \mathrm{~h}, \\
\left.25^{\circ} \mathrm{C}, 1: 40\right) \\
\text { Filtration } \\
\text { Freeze drying } \\
\text { Grinding }\end{array}$ & $\begin{array}{l}\text { Solid liquid extraction } \\
\text { and sonication at } \\
\text { scheduled times by } \\
\text { high-intensity } \\
\text { ultrasonic disintegrator } \\
\text { (1000 s, } 200 \text { cycles, } 5 \text { on, } \\
5 \text { off, } 15 \mu \text { m of probe } \\
\text { amplitude) } \\
\text { EtOH: } \mathrm{H}_{2} \mathrm{O}(70: 30 v / v) \\
1: 32 \\
48 \mathrm{~h} \\
25^{\circ} \mathrm{C}\end{array}$ & $\begin{array}{c}\text { Centrifugation } \\
(8000 \mathrm{rpm}, \\
30 \mathrm{~min}, \times 2) \\
\text { Concentration } \\
\text { under rotavapor } \\
\text { Freeze drying } \\
\text { Loading into } \\
\text { vesicles (liposomes, } \\
\text { montanov- } \\
\text { glycerosomes, } \\
\text { glycerosomes and } \\
\text { montanov- } \\
\text { liposomes) }\end{array}$ & $\begin{array}{l}\text { Folin-Ciocalteu } \\
\text { and } \\
\text { DPPH assays }\end{array}$ & $\begin{array}{l}\text { HPLC-ESI- } \\
\text { TOF-MS }\end{array}$ & $\begin{array}{l}\text { Both samples contained: } \\
\text { Catechin isomers, fisetin, } \\
\text { quercetin, myricetin, quercetin } \\
\text { hexoside, syringetin hexoside, } \\
\text { quercetin-3-methyletere, } \\
\text { apigenin-6,8-di-C-arabinoside } \\
\text { and apigenin-6,8-di-C-arabinoside } \\
\text { Sample not pre-treated: } \\
\text { Syringic acid and } \\
\text { myricetin hexoside } \\
\text { Sample pre-treated: } \\
\text { Epicatechin gallate }\end{array}$ & Yes & No & No & $\begin{array}{l}\text { Antioxidant } \\
\text { Cellular } \\
\text { protection }\end{array}$ & [38] \\
\hline
\end{tabular}


Table 1. Cont.

\begin{tabular}{|c|c|c|c|c|c|c|c|c|c|c|c|}
\hline \multirow{2}{*}{$\begin{array}{c}\text { Grape } \\
\text { Variety/Fruit } \\
\text { Part } \\
\end{array}$} & \multirow{2}{*}{$\begin{array}{c}\text { Pre- } \\
\text { Treatment }\end{array}$} & \multirow{2}{*}{$\begin{array}{l}\text { Extraction Parameters } \\
\text { (Method; Solvent; } \\
\text { Solid to Liquid Ratio; } \\
\text { Time; Temperature) }\end{array}$} & \multirow{2}{*}{$\begin{array}{c}\text { Extract } \\
\text { Treatment }\end{array}$} & \multirow{2}{*}{$\begin{array}{l}\text { Spectrophotometric } \\
\text { Methods }\end{array}$} & \multirow{2}{*}{$\begin{array}{l}\text { Chromatographic } \\
\text { Methods }\end{array}$} & \multirow{2}{*}{$\begin{array}{l}\text { Identified Phenolic } \\
\text { Compounds }\end{array}$} & \multirow{2}{*}{$\begin{array}{c}\text { Analysis } \\
\text { on Extract } \\
\text { In Vitro }\end{array}$} & \multicolumn{2}{|c|}{$\begin{array}{l}\text { Incorporation in } \\
\text { Product }\end{array}$} & \multirow{2}{*}{$\begin{array}{l}\text { Studied } \\
\text { Activity }\end{array}$} & \multirow[t]{2}{*}{ Ref } \\
\hline & & & & & & & & In Vitro & In Vivo & & \\
\hline \multirow{2}{*}{$\begin{array}{c}\text { Vitis } \\
\text { vinifera/seeds } \\
\text { paste }\end{array}$} & \multirow{2}{*}{$\begin{array}{l}\text { Cold pressing } \\
\text { of seeds } \\
\text { Defatting of } \\
\text { the seed pastes }\end{array}$} & $\begin{array}{c}\text { Ultrasound extraction } \\
\text { EtOH and EtOH: } \mathrm{H}_{2} \mathrm{O} \\
(1: 1 \mathrm{v} / \mathrm{v}) \\
1: 3 \\
20 \mathrm{~min}\end{array}$ & $\begin{array}{l}\text { Evaporation to } \\
\text { dryness }\end{array}$ & \multirow[t]{2}{*}{$\begin{array}{l}\text { Folin-Ciocalteu and } \\
\text { DPPH assays }\end{array}$} & \multirow[t]{2}{*}{$\begin{array}{l}\text { HPLC-DAD and } \\
\text { LC-HRMS }\end{array}$} & $\begin{array}{l}\text { Gluconic acid, tartaric acid, citric } \\
\text { acid, gallic acid, glucogalli, } \\
\text { catechin, epicatechin, } \\
\text { epicatechin gallate, dimer and } \\
\text { trimer and tetramer } \\
\text { proanthocyanidins, dimer } \\
\text { and trimer } \\
\text { proanthocyanidins gallate } \\
\end{array}$ & \multirow[t]{2}{*}{ Yes } & \multirow[t]{2}{*}{ No } & \multirow[t]{2}{*}{ No } & \multirow{2}{*}{$\begin{array}{l}\text { Antioxidant } \\
\text { Inhibition } \\
\text { activity } \\
\text { against col- } \\
\text { lagenase, } \\
\text { elastase } \\
\text { and } \\
\text { tyrosinase } \\
\text { enzymes }\end{array}$} & \multirow[t]{2}{*}[40]{} \\
\hline & & $\begin{array}{c}\text { Supercritical fluid } \\
\text { extraction ( } 300 \text { bar) } \\
\mathrm{CO}_{2} \text { at } 15 \mathrm{~g} / \mathrm{min} \text { with } \\
10 \% \mathrm{EtOH} \text { and } \mathrm{CO}_{2} \text { at } \\
15 \mathrm{~g} / \mathrm{min} \text { with } 20 \% \\
\text { EtOH } w / w\end{array}$ & - & & & $\begin{array}{l}\text { Gluconic acid, tartaric acid, } \\
\text { citric acid, gallic acid, } \\
\text { glucogalli, catechin } \\
\text { and epicatechin }\end{array}$ & & & & & \\
\hline Grape/seeds & Grinding & $\begin{array}{l}\text { Maceration extraction } \\
\text { EtOH: } \mathrm{H}_{2} \mathrm{O}(95: 5 v / v) \\
1 \text { week }\end{array}$ & $\begin{array}{c}\text { Filtration } \\
\text { (Whatman grade } \\
1 \text { size) } \\
\text { Concentration } \\
\text { under rotavapor } \\
\quad\left(40^{\circ} \mathrm{C}\right) \\
\end{array}$ & - & HPLC & Catechin and epicatechin & Yes & Yes & No & Photoprotectior & $n[41]$ \\
\hline $\begin{array}{l}\text { Vitis viniferaL. } \\
\text { Cabernet Sauvi- } \\
\text { gnon/pomace }\end{array}$ & $\begin{array}{c}\text { Drying } \\
\text { Pulverizing }\end{array}$ & $\begin{array}{l}\text { Percolation extraction } \\
\text { EtOH: } \mathrm{H}_{2} \mathrm{O}(70: 30 v / v)\end{array}$ & $\begin{array}{l}\text { Concentration } \\
\text { (ascending film } \\
\text { evaporator) } \\
\text { Homogenization } \\
\text { Freeze drying } \\
\end{array}$ & - & - & - & No & Yes & Yes & Photoprotectior & $n[45]$ \\
\hline $\begin{array}{c}\text { Vitis viniferaL. } \\
\text { Red varieties: } \\
\text { Tinta Roriz, } \\
\text { Touriga } \\
\text { Nacional, } \\
\text { Castelão and } \\
\text { Syrah/stems } \\
\text { White varieties: } \\
\text { Arinto, and } \\
\text { Fernão } \\
\text { Pires/stems }\end{array}$ & Grinding & $\begin{array}{c}\text { Solid liquid extraction } \\
\mathrm{MeOH}: \mathrm{H}_{2} \mathrm{O}(70: 30 \\
v / v) \\
0.4: 15 \\
30 \mathrm{~min} \\
\text { Room temperature }\end{array}$ & $\begin{array}{c}\text { Centrifugation } \\
(10,000 \mathrm{rpm}, 15 \\
\left.\text { min, at } 4^{\circ} \mathrm{C}\right) \\
\text { Filtration }(0.45 \\
\mu \mathrm{m} \text { PVDF filter })\end{array}$ & $\begin{array}{c}\text { ABTS, DPPH, } \\
\text { and FRAP assays }\end{array}$ & $\begin{array}{l}\text { Reversed phase- } \\
\text { HPLC-DAD }\end{array}$ & $\begin{array}{l}\text { Gallic acid, protocatechuic acid, } \\
\text { catechin, epicatechin, } \\
\text { trans-cinnamic acid, caftaric } \\
\text { acid, quercetin-3-O-rutinoside, } \\
\text { resveratrol, } \varepsilon \text {-viniferin, } \\
\text { malvidin-3-O-galactoside, } \\
\text { malvidin-3-O-glucoside }\end{array}$ & Yes & No & No & $\begin{array}{l}\text { Antioxidant } \\
\text { and } \\
\text { inhibition } \\
\text { activity } \\
\text { against } \\
\text { elastase } \\
\text { and } \\
\text { tyrosinase } \\
\text { enzymes }\end{array}$ & {$[46]$} \\
\hline
\end{tabular}


Table 1. Cont.

\begin{tabular}{|c|c|c|c|c|c|c|c|c|c|c|c|}
\hline \multirow{2}{*}{$\begin{array}{c}\text { Grape } \\
\text { Variety/Fruit } \\
\text { Part }\end{array}$} & \multirow{2}{*}{$\begin{array}{c}\text { Pre- } \\
\text { Treatment }\end{array}$} & \multirow{2}{*}{$\begin{array}{l}\text { Extraction Parameters } \\
\text { (Method; Solvent; } \\
\text { Solid to Liquid Ratio; } \\
\text { Time; Temperature) }\end{array}$} & \multirow{2}{*}{$\begin{array}{l}\text { Extract } \\
\text { Treatment }\end{array}$} & \multirow{2}{*}{$\begin{array}{l}\text { Spectrophotometric } \\
\text { Methods }\end{array}$} & \multirow{2}{*}{$\begin{array}{l}\text { Chromatographic } \\
\text { Methods }\end{array}$} & \multirow[t]{2}{*}{$\begin{array}{l}\text { Identified Phenolic } \\
\text { Compounds }\end{array}$} & \multirow{2}{*}{$\begin{array}{l}\text { Analysis } \\
\text { on Extract } \\
\text { In Vitro }\end{array}$} & \multicolumn{2}{|c|}{$\begin{array}{l}\text { Incorporation in } \\
\text { Product }\end{array}$} & \multirow[t]{2}{*}{$\begin{array}{l}\text { Studied } \\
\text { Activity }\end{array}$} & \multirow[t]{2}{*}{$\operatorname{Re}$} \\
\hline & & & & & & & & In Vitro & In Vivo & & \\
\hline $\begin{array}{l}\text { Tempranillo } \\
\text { /pomace }\end{array}$ & $\begin{array}{l}\text { With and } \\
\text { without } \\
\text { microwaves } \\
\text { irradiation } \\
\left(80^{\circ} \mathrm{C} \text { for } 60\right. \\
\mathrm{s})\end{array}$ & $\begin{array}{l}\text { Solid liquid extraction } \\
\text { EtOH: } \mathrm{H}_{2} \mathrm{O}(50: 50 v / v) \\
60{ }^{\circ} \mathrm{C}\end{array}$ & $\begin{array}{l}\text { Concentration } \\
\text { under rotavapor }\end{array}$ & $\begin{array}{c}\text { Folin-Ciocalteu, } \\
\text { total monomeric } \\
\text { anthocyanin } \\
\text { pigment content, } \\
\text { ORAC, HOSC } \\
\text { and HORAC } \\
\text { assays }\end{array}$ & $\begin{array}{l}\text { HPLC-DAD- } \\
\text { MS/MS }\end{array}$ & $\begin{array}{c}\text { Gallic acid, } \\
\text { 2-S-glutathionylcaftaric acid, } \\
\text { procyanidin dimer and trimer, } \\
\text { caftaric acid, catechin, } \\
\text { epicatechin, } \\
\text { delphinidin-3-O-glucoside, } \\
\text { quercetin-3-O-glucoside, } \\
\text { coutaric acid, } \\
\text { cyanidin-3-O-glucoside, visitin } \\
\text { A, petunidin-3-O-glucoside, } \\
\text { myricetin-3-O-glucoside, } \\
\text { malvidin-3-O-glucoside, } \\
\text { peonidin-3-O-glucoside, } \\
\text { quercetin-3-O-glucuronide, } \\
\text { delphinidin-3-O-6"-p- } \\
\text { acetylglucoside, } \\
\text { 10-carboxypyranomalvidin-3- } \\
\text { 6"-p-coumaroylglucoside, } \\
\text { syringetin-3-O-glucoside, } \\
\text { myricetin, cyanidin-3-O-6"-p- } \\
\text { coumaroylglucoside, } \\
\text { petunidin-3-O-6"- }-p- \\
\text { coumaroylglucoside, quercetin, } \\
\text { malvidin-3-O-6"- } p \text { - } \\
\text { coumaroylglucoside, } \\
\text { peonidin-3-O-6"- }-p \text { - } \\
\text { coumaroylglucoside, } \\
\text { kaempferol }\end{array}$ & Yes & No & No & $\begin{array}{l}\text { Inhibition } \\
\text { activity } \\
\text { against } \\
\text { elastase, } \\
\text { tyrosinase } \\
\text { and MMP-1 } \\
\text { enzymes } \\
\text { Antioxidant } \\
\text { activity }\end{array}$ & [37] \\
\hline Grape/seeds & Crushing & $\begin{array}{c}\text { Maceration extraction } \\
\text { EtOH: } \mathrm{H}_{2} \mathrm{O}(95: 5 v / v) \\
1: 3 \\
1 \text { week }\end{array}$ & $\begin{array}{c}\text { Filtration } \\
\text { Concentration } \\
\text { under rotavapor } \\
\left(40^{\circ} \mathrm{C}\right)\end{array}$ & $\begin{array}{l}\text { Folin-Ciocalteu, } \\
\text { total monomeric } \\
\text { anthocyanin } \\
\text { content, DPPH } \\
\text { and FRAP assays }\end{array}$ & - & - & Yes & Yes & No & Photoprotectior & a[42] \\
\hline
\end{tabular}


Table 1. Cont.

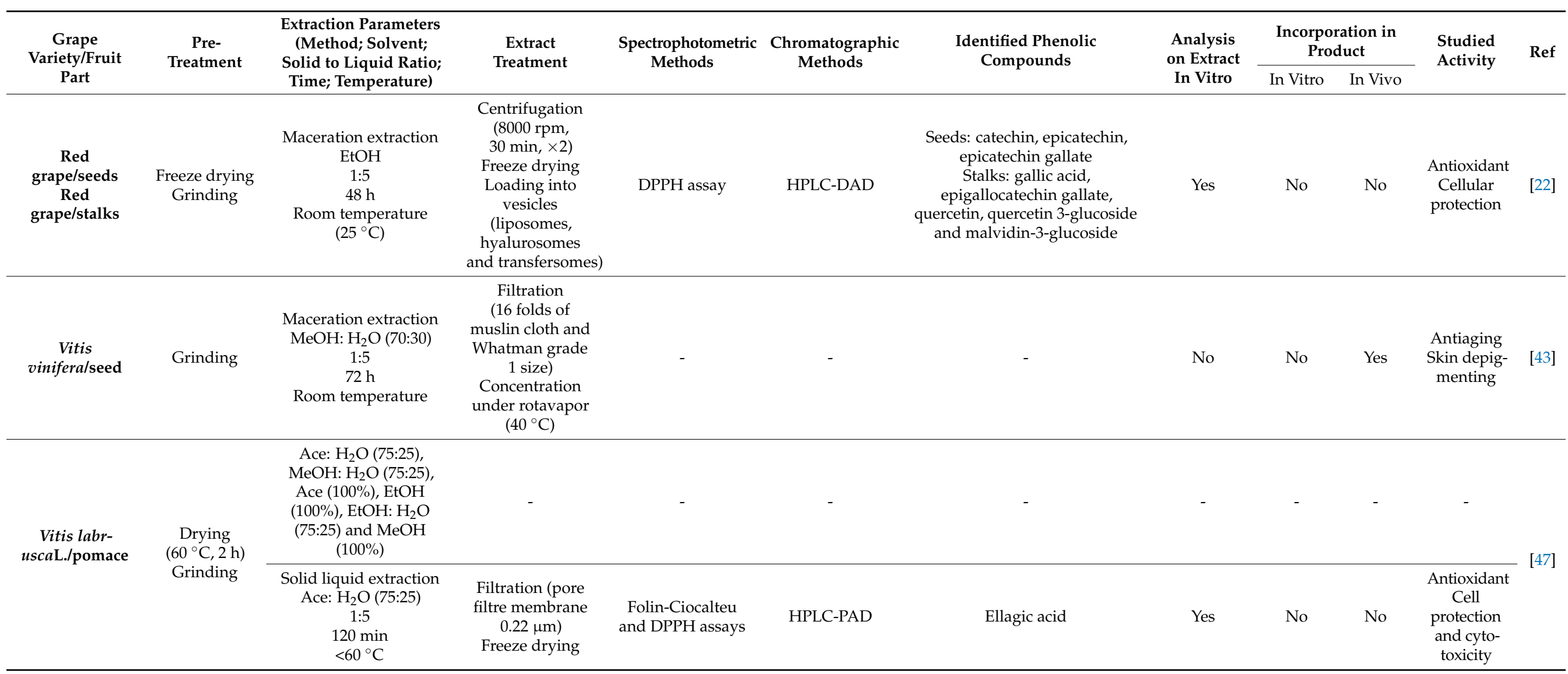


Table 1. Cont.

\begin{tabular}{|c|c|c|c|c|c|c|c|c|c|c|c|}
\hline \multirow{2}{*}{$\begin{array}{c}\text { Grape } \\
\text { Variety/Fruit } \\
\text { Part }\end{array}$} & \multirow{2}{*}{$\begin{array}{c}\text { Pre- } \\
\text { Treatment }\end{array}$} & \multirow{2}{*}{$\begin{array}{l}\text { Extraction Parameters } \\
\text { (Method; Solvent; } \\
\text { Solid to Liquid Ratio; } \\
\text { Time; Temperature) }\end{array}$} & \multirow{2}{*}{$\begin{array}{c}\text { Extract } \\
\text { Treatment }\end{array}$} & \multirow{2}{*}{$\begin{array}{l}\text { Spectrophotometric } \\
\text { Methods }\end{array}$} & \multirow{2}{*}{$\begin{array}{l}\text { Chromatographic } \\
\text { Methods }\end{array}$} & \multirow{2}{*}{$\begin{array}{l}\text { Identified Phenolic } \\
\text { Compounds }\end{array}$} & \multirow{2}{*}{$\begin{array}{c}\text { Analysis } \\
\text { on Extract } \\
\text { In Vitro }\end{array}$} & \multicolumn{2}{|c|}{$\begin{array}{c}\text { Incorporation in } \\
\text { Product }\end{array}$} & \multirow{2}{*}{$\begin{array}{l}\text { Studied } \\
\text { Activity }\end{array}$} & \multirow[t]{2}{*}{ Ref } \\
\hline & & & & & & & & In Vitro & In Vivo & & \\
\hline $\begin{array}{l}\text { Mix of Vitis } \\
\text { vinifera L. } \\
\text { Trebbiano \& } \\
\text { Verdicchio } \\
(60: 40) / \text { pomace }\end{array}$ & $\begin{array}{l}\text { Wet pomace: } \\
\text { Grinding and } \\
\text { addition of } \\
\text { distilled } \\
\text { water } \\
(1: 5 \mathrm{~g} / \mathrm{mL})\end{array}$ & $\begin{array}{c}\text { Enzyme-assisted } \\
\text { extraction } \\
\mathrm{H}_{2} \mathrm{O}(100 \%) \text { and EtOH: } \\
\mathrm{H}_{2} \mathrm{O}(95: 5 \mathrm{v} / \mathrm{v}) \\
\text { Overnight } \\
24^{\circ} \mathrm{C}\end{array}$ & - & $\begin{array}{l}\text { Folin-Ciocalteu, } \\
\text { flavonoid and } \\
\text { flavanol content } \\
\text { assays }\end{array}$ & HPLC-DAD & $\begin{array}{c}\text { Catechin, epicatechin, } \\
\text { epigallocatechin gallate, } \\
\text { epicatechin gallate, } \\
\text { epigallocatechin, gallic acid, } \\
\text { cis-piceid, cis- resveratroloside. }\end{array}$ & & & & $\begin{array}{l}\text { Anti- } \\
\text { tyrosinase } \\
\text { Anti- } \\
\text { elastase }\end{array}$ & [44] \\
\hline Grape/seeds & - & Purchased extract & - & - & - & - & Yes & Yes & No & $\begin{array}{c}\text { Photo- } \\
\text { protection }\end{array}$ & [50] \\
\hline Grape/seeds & - & - & - & DPPH assay & - & - & Yes & No & Yes & Antiaging & [51] \\
\hline $\begin{array}{l}\text { Muscat Ham- } \\
\text { burg/seeds }\end{array}$ & Grinding & $\begin{array}{c}\text { Sonication } \\
\text { MetOH: } \mathrm{H}_{2} \mathrm{O}: 1 \mathrm{M} \mathrm{HCl} \\
(70: 29.5: 0.5) \\
1: 5 \\
15 \text { to } 20 \mathrm{~min}\end{array}$ & $\begin{array}{l}\text { Filtration } \\
\text { (Whatman } \\
\text { grade 1) } \\
\text { Concentration } \\
\text { under rotavapor } \\
\text { Filtration }\end{array}$ & - & - & - & No & No & Yes & $\begin{array}{l}\text { Skin depig- } \\
\text { menting } \\
\text { Moisturizing } \\
\text { Antiaging }\end{array}$ & [53] \\
\hline
\end{tabular}

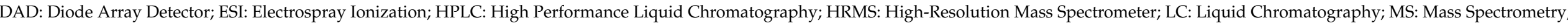

PAD: Photodiode Array Detector; TOF: Time Of Flight. 
Table 2. In vitro assays conducted on grape pomace extracts with their corresponding studied and effective concentrations as well as their observed effects.

\begin{tabular}{|c|c|c|c|c|c|c|c|}
\hline $\begin{array}{l}\text { Grape Variety/ } \\
\text { Fruit Part }\end{array}$ & Studied Activity & Type of Assay & Sample & $\begin{array}{c}\text { Studied } \\
\text { Concentrations }\end{array}$ & $\begin{array}{c}\text { Effective } \\
\text { Concentration }\end{array}$ & Observed Effect & Ref \\
\hline \multirow{6}{*}{ Carignano/skins } & \multirow{3}{*}{ Antioxidant activity } & \multirow{3}{*}{ DPPH assay } & Extract in dispersion & - & $30 \mathrm{mg} / \mathrm{mL}$ & $\begin{array}{l}84 \% \text { reduction of } \\
\text { DPPH radicals }\end{array}$ & \multirow{6}{*}{ [38] } \\
\hline & & & $\begin{array}{l}\text { Extract-loaded vesicles } \\
\text { (glycerosomes) }\end{array}$ & - & $30 \mathrm{mg} / \mathrm{mL}$ & $\begin{array}{l}88 \% \text { reduction of } \\
\text { DPPH radicals }\end{array}$ & \\
\hline & & & $\begin{array}{l}\text { Extract-loaded vesicles } \\
\text { (liposomes) }\end{array}$ & - & $30 \mathrm{mg} / \mathrm{mL}$ & $\begin{array}{l}90 \% \text { reduction of } \\
\text { DPPH radicals }\end{array}$ & \\
\hline & \multirow{3}{*}{$\begin{array}{l}\text { Cellular protection in } \\
\text { the presence of } \mathrm{H}_{2} \mathrm{O}_{2}\end{array}$} & \multirow{3}{*}{$\begin{array}{l}\text { Fibroblast cell } \\
\text { culture }\end{array}$} & Extract in dispersion & \multirow[b]{2}{*}{$0.3,3$ and 30 and $\mu \mathrm{g} / \mathrm{mL}$} & $0.3 \mu \mathrm{g} / \mathrm{mL}$ & $\begin{array}{l}\text { Increased viability of } \\
\text { fibroblasts to } 70 \%\end{array}$ & \\
\hline & & & $\begin{array}{l}\text { Extract-loaded vesicles } \\
\text { (liposomes, } \\
\text { montanov-liposomes, } \\
\text { montanov-glycerosomes } \\
\text { and glycerosomes) }\end{array}$ & & $0.3 \mu \mathrm{g} / \mathrm{mL}$ & $\begin{array}{l}\text { Increased viability of } \\
\text { fibroblasts } \geq 83 \%\end{array}$ & \\
\hline & & & $\begin{array}{l}\text { Positive control (treated } \\
\text { cells with } \mathrm{H}_{2} \mathrm{O}_{2} \text { ) }\end{array}$ & - & - & $\begin{array}{l}\text { Reduction of the viability } \\
\text { of fibroblasts to } 50 \%\end{array}$ & \\
\hline \multirow{5}{*}{$\begin{array}{l}\text { Vitis viniferal } \\
\text { seeds paste }\end{array}$} & \multirow{5}{*}{$\begin{array}{l}\text { Anti-tyrosinase } \\
\text { activity }\end{array}$} & \multirow{5}{*}{ Enzymatic assay } & Ultrasound extract in $\mathrm{EtOH}$ & 20,150 and $500 \mu \mathrm{g} / \mathrm{mL}$ & $500 \mu \mathrm{g} / \mathrm{mL}$ & $\begin{array}{l}\text { Up to } 75 \% \text { decrease of } \\
\text { tyrosinase activity }\end{array}$ & \multirow{5}{*}{ [40] } \\
\hline & & & $\begin{array}{l}\text { Ultrasound extract in EtOH: } \\
\qquad \mathrm{H}_{2} \mathrm{O}(1: 1)\end{array}$ & 20,150 and $500 \mu \mathrm{g} / \mathrm{mL}$ & $500 \mu \mathrm{g} / \mathrm{mL}$ & $\begin{array}{l}\text { Up to } 72.4 \% \text { decrease of } \\
\text { tyrosinase activity }\end{array}$ & \\
\hline & & & $\begin{array}{l}\text { Supercritical fluid extract } \\
(10 \% \mathrm{EtOH})\end{array}$ & 20,150 and $500 \mu \mathrm{g} / \mathrm{mL}$ & $500 \mu \mathrm{g} / \mathrm{mL}$ & $\begin{array}{l}\text { Up to } 10 \% \text { decrease of } \\
\text { tyrosinase activity }\end{array}$ & \\
\hline & & & $\begin{array}{l}\text { Supercritical fluid extract } \\
(20 \% \mathrm{EtOH})\end{array}$ & 20,150 and $500 \mu \mathrm{g} / \mathrm{mL}$ & $500 \mu \mathrm{g} / \mathrm{mL}$ & $\begin{array}{l}\text { Up to } 15 \% \text { decrease of } \\
\text { tyrosinase activity }\end{array}$ & \\
\hline & & & Positive control: kojic acid & - & $7.1 \mu \mathrm{g} / \mathrm{mL}$ & $\begin{array}{l}\text { Up to } 52 \% \text { decrease of } \\
\text { tyrosinase activity }\end{array}$ & \\
\hline
\end{tabular}


Table 2. Cont.

\begin{tabular}{|c|c|c|c|c|c|c|c|}
\hline $\begin{array}{l}\text { Grape Variety/Fruit } \\
\text { Part }\end{array}$ & Studied Activity & Type of Assay & Sample & $\begin{array}{c}\text { Studied } \\
\text { Concentrations }\end{array}$ & $\begin{array}{c}\text { Effective } \\
\text { Concentration }\end{array}$ & Observed Effect & Ref \\
\hline \multirow{7}{*}{$\begin{array}{l}\text { Vitis viniferal } \\
\text { seeds paste }\end{array}$} & \multirow{4}{*}{ Anti-elastase activity } & \multirow{4}{*}{ Enzymatic assay } & Ultrasound extract in $\mathrm{EtOH}$ & $\begin{array}{l}30,150 \text { and } \\
300 \mu \mathrm{g} / \mathrm{mL}\end{array}$ & $300 \mu \mathrm{g} / \mathrm{mL}$ & $\begin{array}{l}\text { Up to } 91.3 \% \text { decrease of } \\
\text { elastase activity }\end{array}$ & \multirow{7}{*}[40]{} \\
\hline & & & $\begin{array}{l}\text { Ultrasound extract in EtOH: } \\
\qquad \mathrm{H}_{2} \mathrm{O}(1: 1)\end{array}$ & $\begin{array}{l}30,150 \text { and } \\
300 \mu \mathrm{g} / \mathrm{mL}\end{array}$ & $300 \mu \mathrm{g} / \mathrm{mL}$ & $\begin{array}{c}\text { Up to } 83.2 \% \text { decreasing of } \\
\text { elastase activity }\end{array}$ & \\
\hline & & & $\begin{array}{l}\text { Supercritical fluid extract } \\
\qquad(10 \% \mathrm{EtOH})\end{array}$ & $\begin{array}{l}30,150 \text { and } \\
300 \mu \mathrm{g} / \mathrm{mL}\end{array}$ & $300 \mu \mathrm{g} / \mathrm{mL}$ & $\begin{array}{l}\text { Up to } 30 \% \text { decrease of } \\
\text { elastase activity }\end{array}$ & \\
\hline & & & Positive control: Elastatinal & - & $0.5 \mu \mathrm{g} / \mathrm{mL}$ & $\begin{array}{l}\text { Up to } 51.3 \% \text { decrease of } \\
\text { elastase activity }\end{array}$ & \\
\hline & \multirow{3}{*}{$\begin{array}{l}\text { Anti-collagenase } \\
\text { activity }\end{array}$} & \multirow{3}{*}{ Enzymatic assay } & $\begin{array}{l}\text { Ultrasound extract in EtOH } \\
\text { and EtOH: } \mathrm{H}_{2} \mathrm{O}(1: 1)\end{array}$ & 50,200 and $600 \mu \mathrm{g} / \mathrm{mL}$ & $200 \mu \mathrm{g} / \mathrm{mL}$ & $\begin{array}{l}\text { Up to } 100 \% \text { decrease of } \\
\text { collagenase activity }\end{array}$ & \\
\hline & & & $\begin{array}{l}\text { Supercritical fluid extract } \\
(20 \% \mathrm{EtOH})\end{array}$ & 50,200 and $600 \mu \mathrm{g} / \mathrm{mL}$ & $600 \mu \mathrm{g} / \mathrm{mL}$ & $\begin{array}{l}\text { Up to } 90 \% \text { decrease of } \\
\text { collagenase activity }\end{array}$ & \\
\hline & & & $\begin{array}{l}\text { Positive control: } \\
\text { Phosphoramidon }\end{array}$ & - & $16 \mu \mathrm{M}$ & $\begin{array}{l}\text { Up to } 46.4 \% \text { decrease of } \\
\text { collagenase activity }\end{array}$ & \\
\hline \multirow[b]{2}{*}{ Grape/seeds } & Cytotoxicity & $\begin{array}{l}\text { MTT assay on } \\
\text { fibroblast cell } \\
\text { culture }\end{array}$ & Extract & 0.1 to $31.25 \mu \mathrm{g} / \mathrm{mL}$ & $31.25 \mu \mathrm{g} / \mathrm{mL}$ & $\begin{array}{l}\text { Dose-dependent and } \\
\text { significant increased } \\
\text { fibroblast viability } \\
\text { by up to } 132 \%\end{array}$ & \multirow[b]{2}{*}{ [41] } \\
\hline & UV protection & $\begin{array}{l}\text { MTT assay on } \\
\text { irradiated } \\
\text { fibroblasts with } \\
\text { UVA }\left(20 \mathrm{~J} . \mathrm{cm}^{-2}\right)\end{array}$ & Extract & 0.1 to $25 \mu \mathrm{g} / \mathrm{mL}$ & $25 \mu \mathrm{g} / \mathrm{mL}$ & $\begin{array}{c}\text { Improved cell viability by } \\
\text { up to } 68 \%\end{array}$ & \\
\hline
\end{tabular}


Table 2. Cont

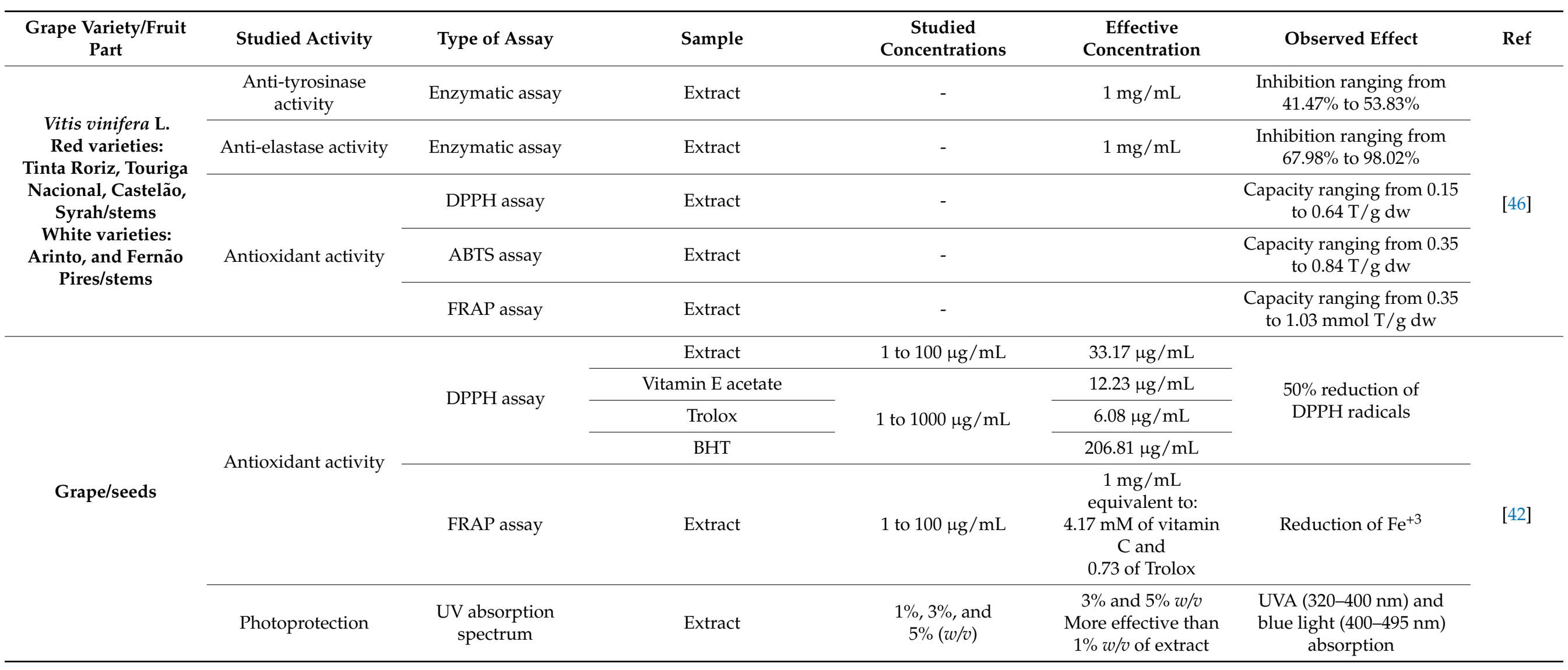


Table 2. Cont.

\begin{tabular}{|c|c|c|c|c|c|c|c|}
\hline $\begin{array}{l}\text { Grape Variety/Fruit } \\
\text { Part }\end{array}$ & Studied Activity & Type of Assay & Sample & $\begin{array}{c}\text { Studied } \\
\text { Concentrations }\end{array}$ & $\begin{array}{c}\text { Effective } \\
\text { Concentration }\end{array}$ & Observed Effect & Ref \\
\hline \multirow{15}{*}{ Tempranillo/pomace } & \multirow{2}{*}{$\begin{array}{l}\text { Anti-tyrosinase } \\
\text { activity }\end{array}$} & \multirow{5}{*}{ Enzymatic assay } & Extract without irradiation & \multirow{5}{*}{$\begin{array}{l}\text { Increasing } \\
\text { concentration }\end{array}$} & $4.03 \pm 0.14 \mathrm{mg} / \mathrm{mL}$ & \multirow{2}{*}{$\begin{array}{l}50 \% \text { reduction of } \\
\text { tyrosinase activity }\end{array}$} & \multirow{15}{*}[37]{} \\
\hline & & & MW irradiated extract & & $4.00 \pm 0.14 \mathrm{mg} / \mathrm{mL}$ & & \\
\hline & \multirow{2}{*}{ Anti-elastase activity } & & Extract without irradiation & & $0.87 \pm 0.03 \mathrm{mg} / \mathrm{mL}$ & \multirow{2}{*}{$\begin{array}{l}50 \% \text { reduction of } \\
\text { elastase activity }\end{array}$} & \\
\hline & & & MW irradiated extract & & $3.43 \pm 0.11 \mathrm{mg} / \mathrm{mL}$ & & \\
\hline & Anti- MMP-1 activity & & Extract without irradiation & & $1.08 \pm 0.08 \mathrm{mg} / \mathrm{mL}$ & $\begin{array}{l}50 \% \text { reduction of } \\
\text { MMP-1 activity }\end{array}$ & \\
\hline & \multirow{6}{*}{ Antioxidant activity } & \multirow{2}{*}{ ORAC assay } & Extract without irradiation & & & $\begin{array}{c}481 \pm 30 \mu \mathrm{mol} \mathrm{TE} / \mathrm{g} \\
\text { Extract }\end{array}$ & \\
\hline & & & MW irradiated extract & & & $\begin{array}{c}448 \pm 31 \mu \mathrm{mol} \mathrm{TE} / \mathrm{g} \\
\text { Extract }\end{array}$ & \\
\hline & & HOC & Extract without irradiation & - & - & $\begin{array}{c}746 \pm 49 \mu \mathrm{mol} \mathrm{TE} / \mathrm{g} \\
\text { Extract }\end{array}$ & \\
\hline & & HUSC assay & MW irradiated extract & & & $\begin{array}{c}441 \pm 34 \mu \mathrm{mol} \mathrm{TE} / \mathrm{g} \\
\text { Extract }\end{array}$ & \\
\hline & & HOPA C & Extract without irradiation & & & $\begin{array}{c}305 \pm 28 \mu \mathrm{mol} \text { CAE } / g \\
\text { Extract }\end{array}$ & \\
\hline & & HURAC assay & MW irradiated extract & & & $\begin{array}{c}198 \pm 19 \mu \mathrm{mol} \mathrm{CAE} / \mathrm{g} \\
\text { Extract }\end{array}$ & \\
\hline & \multirow{4}{*}{$\begin{array}{c}\text { Cellular protective } \\
\text { effects against } \\
\text { oxidative damage } \\
\text { (TBHP) }\end{array}$} & \multirow{2}{*}{$\begin{array}{l}\text { keratinocyte cell } \\
\text { culture }\end{array}$} & Extract without irradiation & \multirow{4}{*}{$\begin{array}{l}0.25 \mathrm{mg} / \mathrm{mL} \text { to } \\
2 \mathrm{mg} / \mathrm{mL}\end{array}$} & \multirow{4}{*}{$0.25 \mathrm{mg}$ extract $/ \mathrm{mL}$} & $\begin{array}{c}\text { Cell viability increased } \\
\text { to } 60 \%\end{array}$ & \\
\hline & & & MW irradiated extract & & & $\begin{array}{c}\text { Cell viability } \\
\text { increased to } 45 \%\end{array}$ & \\
\hline & & \multirow{2}{*}{$\begin{array}{l}\text { Fibroblast cell } \\
\text { culture }\end{array}$} & Extract without irradiation & & & $\begin{array}{c}\text { Cell viability increased } \\
\text { to } 50 \%\end{array}$ & \\
\hline & & & MW irradiated extract & & & $\begin{array}{c}\text { Cell viability } \\
\text { increased to } 20 \%\end{array}$ & \\
\hline
\end{tabular}


Table 2. Cont

\begin{tabular}{|c|c|c|c|c|c|c|c|}
\hline $\begin{array}{c}\text { Grape Variety/Fruit } \\
\text { Part }\end{array}$ & Studied Activity & Type of Assay & Sample & $\begin{array}{c}\text { Studied } \\
\text { Concentrations }\end{array}$ & $\begin{array}{c}\text { Effective } \\
\text { Concentration }\end{array}$ & Observed Effect & Ref \\
\hline \multirow{4}{*}{$\begin{array}{l}\text { Red grape/seeds } \\
\text { Red grape/stalks }\end{array}$} & \multirow[b]{2}{*}{ Antioxidant } & \multirow[b]{2}{*}{ DPPH assay } & Extract in dispersion & - & $40 \mu \mathrm{g} / \mathrm{mL}$ & $\begin{array}{l}78 \% \text { reduction of } \\
\text { DPPH radicals }\end{array}$ & \multirow{4}{*}{ [22] } \\
\hline & & & $\begin{array}{c}\text { Extract loaded vesicles } \\
\text { (liposomes, transfersomes, } \\
\text { hyalurosomes, } \\
\text { hyalo-transfersomes) }\end{array}$ & - & $40 \mu \mathrm{g} / \mathrm{mL}$ & $\begin{array}{l}88 \% \text { reduction of } \\
\text { DPPH radicals }\end{array}$ & \\
\hline & \multirow[t]{2}{*}{$\begin{array}{l}\text { Protection in the } \\
\text { presence of } \mathrm{H}_{2} \mathrm{O}_{2}\end{array}$} & \multirow[t]{2}{*}{$\begin{array}{l}\text { Fibroblast and } \\
\text { keratinocyte cell } \\
\text { culture }\end{array}$} & $\begin{array}{c}\text { Extract loaded vesicles } \\
\text { (liposomes, transfersomes, } \\
\text { hyalurosomes, } \\
\text { hyalo-transfersomes) }\end{array}$ & - & $2 \mu \mathrm{g} / \mathrm{mL}$ & $\begin{array}{l}\text { Viability increased }>100 \% \\
\text { in both cell lines }\end{array}$ & \\
\hline & & & $\begin{array}{c}\text { Positive control (exposed to } \\
\mathrm{H}_{2} \mathrm{O}_{2} \text { and untreated } \\
\text { with extract) }\end{array}$ & - & - & $\begin{array}{l}\text { Viability of keratinocytes } \\
\text { and fibroblasts reduced to } \\
\sim 65 \text { and } 70 \%\end{array}$ & \\
\hline \multirow{7}{*}{$\begin{array}{c}\text { Vitis } \\
\text { labruscaL./pomace }\end{array}$} & \multirow{3}{*}{ Antioxidant } & \multirow{3}{*}{ DPPH assay } & Extract & 0.5 to $25 \mu \mathrm{g} / \mathrm{mL}$ & $6.9 \mu \mathrm{g} / \mathrm{mL}$ & $\begin{array}{l}50 \% \text { reduction of } \\
\text { DPPH radicals }\end{array}$ & \multirow{7}{*}[47]{} \\
\hline & & & BHT & 0.11 to $19 \mu \mathrm{g} / \mathrm{mL}$ & $7.6 \mu \mathrm{g} / \mathrm{mL}$ & $\begin{array}{l}50 \% \text { reduction of } \\
\text { DPPH radicals }\end{array}$ & \\
\hline & & & Quercetin & 0.75 to $15 \mu \mathrm{g} / \mathrm{mL}$ & $4.5 \mu \mathrm{g} / \mathrm{mL}$ & $\begin{array}{l}50 \% \text { reduction of } \\
\text { DPPH radicals }\end{array}$ & \\
\hline & \multirow{2}{*}{ Cytotoxicity } & \multirow{2}{*}{$\begin{array}{l}\text { Fibroblast cell } \\
\text { culture }\end{array}$} & Extract & 0.5 to $200 \mathrm{mg} / \mathrm{mL}$ & $\begin{array}{l}\text { No statically } \\
\text { sionificant }\end{array}$ & \multirow{2}{*}{ Maintained cell viability } & \\
\hline & & & Control (without extract) & - & difference & & \\
\hline & \multirow{2}{*}{$\begin{array}{l}\text { Cytoprotecting in the } \\
\text { presence of } \mathrm{H}_{2} \mathrm{O}_{2} \\
(600 \mu \mathrm{M})\end{array}$} & \multirow{2}{*}{$\begin{array}{l}\text { Fibroblast cell } \\
\text { culture }\end{array}$} & Freeze dried extract & 0.73 to $3.65 \mathrm{mg} / \mathrm{mL}$ & $0.73 \mathrm{mg} / \mathrm{mL}$ & $\begin{array}{l}\text { Maintained cell viability } \\
\text { and protecting against } \\
\qquad \mathrm{H}_{2} \mathrm{O}_{2} \text { damage }\end{array}$ & \\
\hline & & & $\begin{array}{l}\text { Positive control (without } \\
\text { extract) }\end{array}$ & - & - & $\begin{array}{c}\text { Cell viability reduced } \\
\text { to } 60 \%\end{array}$ & \\
\hline
\end{tabular}


Table 2. Cont.

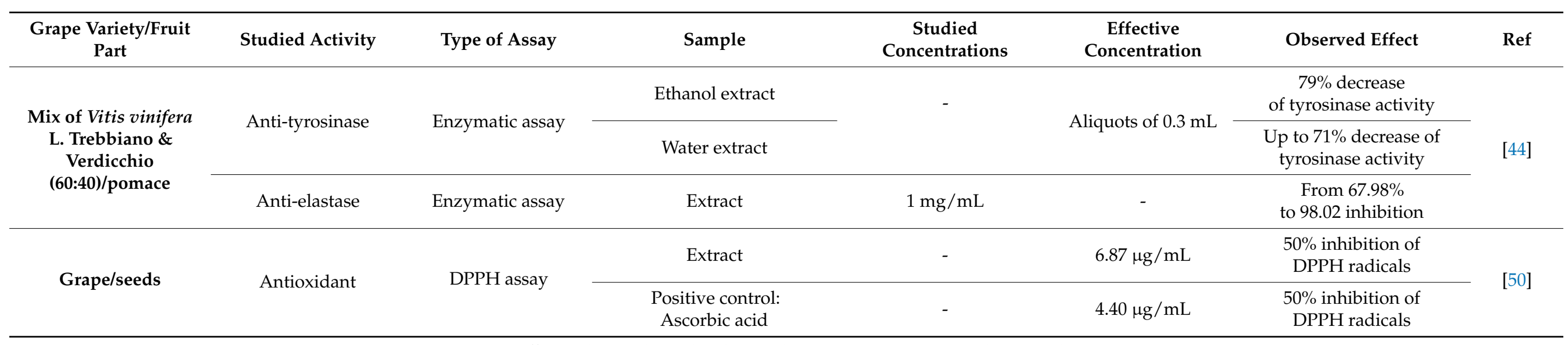

CAE: caffeic acid equivalents; dw: dry weight MW: microwaves; TE: Trolox equivalents. 
Table 3. Formulation of the incorporated grape extracts in different cosmetic products, evaluation and effects.

\begin{tabular}{|c|c|c|c|c|c|c|}
\hline \multirow{2}{*}{ Grape Variety/Fruit Part } & \multirow{2}{*}{ Product } & \multicolumn{3}{|c|}{ Product Evaluation } & \multirow{2}{*}{ Effect } & \multirow{2}{*}{ Ref } \\
\hline & & Stability & In Vitro & In Vivo & & \\
\hline \multirow{2}{*}{ Vitis viniferaL./seeds } & $\begin{array}{l}\text { Emulsion: } \\
\text { Propylene, paraben, paraffin oil, } \\
\text { Abil-EM 90, distilled water, } \\
\text { methylparaben, olive oil, lemon } \\
\text { oil, grape seed extract }(5 \%)\end{array}$ & \multirow{2}{*}{$\begin{array}{l}\text { Rheological studies } \\
\text { Macroscopic } \\
\text { observations }\end{array}$} & \multirow{2}{*}{-} & \multirow{2}{*}{$\begin{array}{c}\text { Skin evaluation } \\
\text { Parameters: skin moisture } \\
\text { content, Sebum content, } \\
\text { elasticity, and SELs } \\
\text { (scaliness, wrinkles, } \\
\text { roughness) } \\
40 \text { females } \\
12 \text { weeks } \\
\text { Cheeks }\end{array}$} & $\begin{array}{c}\text { Reduce: roughness }(14 \%), \\
\text { scaliness }(13 \%) \text {, winkles }(21 \%) \\
\text { and sebum content }(26.13 \%) \\
\text { Enhance: elasticity }(45.3 \%) \\
\text { and hydration }(29.85 \%)\end{array}$ & \multirow{2}{*}{ [49] } \\
\hline & $\begin{array}{l}\text { Emulgel: } \\
\text { Propylene, paraben, paraffin oil, } \\
\text { Abil-EM 90, distilled water, } \\
\text { methylparaben, olive oil, } \\
\text { Carbapol 940, Triethanolamine, } \\
\text { lemon oil, grape seed extract (5\%) }\end{array}$ & & & & $\begin{array}{c}\text { Reduce: roughness }(55 \%), \\
\text { scaliness }(26 \%), \text { winkles } \\
(23.9 \%) \text {, and sebum }(30.3 \%) \\
\text { Enhance: elasticity }(50 \%) \text { and } \\
\text { hydration }(32.2 \%)\end{array}$ & \\
\hline $\begin{array}{l}\text { Vitis vinifera } \mathrm{L} . \\
\text { Grechetto/skin and } \\
\text { seeds }\end{array}$ & $\begin{array}{c}\text { Toothpaste: } \\
2 \% \text { or } 10 \% \text { ethanol skins extract } \\
\text { added into commercial } \\
\text { toothpaste. }\end{array}$ & - & $\begin{array}{l}\text { Total polyphenols } \\
\text { content }\end{array}$ & - & $\begin{array}{l}\text { No significant difference of } \\
\text { polyphenol content between } \\
2 \% \text { and } 10 \% \text { samples. }\end{array}$ & \multirow{3}{*}[39]{} \\
\hline \multirow{2}{*}{$\begin{array}{l}\text { Vitis vinifera } \mathrm{L} . \\
\text { Cabernet } \\
\text { Sauvignon/seeds }\end{array}$} & $\begin{array}{c}\text { Toothpaste: } \\
2.5 \% \text { or } 5 \% \text { of ethanol extract } \\
\text { added into } \\
\text { commercial toothpaste. }\end{array}$ & \multirow[b]{2}{*}{-} & \multirow{2}{*}{$\begin{array}{l}\text { Shelf life evaluation } \\
\text { (after } 2 \text { and } 4 \text { months, at } \\
\text { ambient temperature) by } \\
\text { evaluating: } \\
\text { Total polyphenols } \\
\text { content and } \\
\text { antioxidant activity }\end{array}$} & \multirow{2}{*}{$\begin{array}{c}\text { Acceptability of the } \\
\text { toothpaste was evaluated by } \\
10 \text { consumers }\end{array}$} & $\begin{array}{l}\text { Increase in total polyphenol } \\
\text { content after } 2 \text { months, and } \\
\text { persisted after } 4 \text { months. } \\
\text { Better preservation action in } \\
\text { ethanol than in water. }\end{array}$ & \\
\hline & $\begin{array}{c}\text { Toothpaste: } \\
5 \% \text { or } 10 \% \text { of water extract added } \\
\text { into commercial toothpaste. }\end{array}$ & & & & $\begin{array}{c}\text { Decrease in in total } \\
\text { polyphenol content after } \\
2 \text { months and } 4 \text { months. } \\
\text { Highest antioxidant activity in } \\
10 \% \text { sample. } \\
\text { Most appreciated clinically in } \\
5 \% \text { sample. }\end{array}$ & \\
\hline
\end{tabular}


Table 3. Cont

\begin{tabular}{|c|c|c|c|c|c|c|}
\hline \multirow{2}{*}{ Grape Variety/Fruit Part } & \multirow{2}{*}{ Product } & \multicolumn{3}{|c|}{ Product Evaluation } & \multirow{2}{*}{ Effect } & \multirow{2}{*}{ Ref } \\
\hline & & Stability & In Vitro & In Vivo & & \\
\hline Grape/seeds & $\begin{array}{c}\text { Cream: } \\
\text { Mineral oil }(5 \%), \text { cetomacrogol } \\
1000(7 \%) \text {, cetyl alcohol }(2 \%) \text {, octyl } \\
\text { methoxycinnamate OMC }(7 \%), \\
\text { grape seeds extract }(3 \%), \text { xanthan } \\
(1 \%) \text {, glycerine }(5 \%), \\
\text { phenoxyethanol }(0.5 \%), \text { purified } \\
\text { water q.s. to } 100 \%{ }^{*}\end{array}$ & - & $\begin{array}{l}\text { Photoprotection efficacy: } \\
\text { measurement of UV } \\
\text { emissions before and } \\
\text { after exposure to UV } \\
\text { light using PMMA plates } \\
\text { and Transpore tapes }\end{array}$ & - & $\begin{array}{c}\text { SPF 9.92 on PMMA plates } \\
\text { after UV exposure } \\
\text { SPF 13.64 on Transpore tapes } \\
\text { after UV exposure }\end{array}$ & {$[41]$} \\
\hline \multirow[t]{2}{*}{$\begin{array}{c}\text { Vitis vinifera } \mathrm{L} . \\
\text { Cabernet } \\
\text { Sauvignon/pomace }\end{array}$} & \multirow{2}{*}{$\begin{array}{c}\text { Cream: } \\
\text { Ammonium } \\
\text { acryloyldimethyltaurate/VP } \\
\text { copolymer, trilaureth-4 phosphate, } \\
\text { rapeseed oil sorbitol esters, } \\
\text { mineral oil and isopropyl } \\
\text { palmitate (4\%), ammonium } \\
\text { acryloyldimethyltaurate } \\
\text { vinylpyrrolidone (0.5\%), } \\
\text { propylene glycol (5\%), ethyl } \\
\text { alcohol (2.5\%), disodium EDTA } \\
(0.1 \%), \text { grape pomace extract } \\
(10 \%), \text { water purified q.s. to } 100 \% \text {, } \\
\text { butylmethoxydibenzoyl methane } \\
\text { (2.5\%), ethylhexyl } \\
\text { methoxycinnamate (5\%), } \\
\text { ethylhexyl dimethyl PABA (4\%), } \\
\text { butylated hydroxy toluene }(0.1 \%), \\
\text { mixture of phenoxyethanol and } \\
\text { parabens others }(0.75 \%) *\end{array}$} & \multirow[t]{2}{*}{$\begin{array}{l}\text { Evaluation of } \\
\text { organoleptic properties } \\
\text { by aspect, color, and } \\
\text { odor and the } \mathrm{pH} \text { value. }\end{array}$} & \multirow[t]{2}{*}{$\begin{array}{l}\text { Design of Experiment } \\
\text { DPPH assay } \\
\text { SPF measurement using } \\
\text { PMMA plates }\end{array}$} & $\begin{array}{c}\text { Primary and cumulative } \\
\text { cutaneous irritability and } \\
\text { sensitization tests } \\
60 \text { males and females } \\
6 \text { weeks } \\
\text { Application on the back skin }\end{array}$ & \multirow[t]{2}{*}{$\begin{array}{l}\text { Antioxidant activity }(40.10 \%) \\
\text { Absence of irritation and } \\
\text { dermal sensitization } \\
\text { In vitro SPF: } 16.33 \\
\text { In vivo SPF: } 12.30\end{array}$} & \multirow[t]{2}{*}[45]{} \\
\hline & & & & $\begin{array}{c}\text { Phototoxicity and } \\
\text { Photosensitization test } \\
30 \text { males and females } \\
5 \text { weeks } \\
\text { Applications on the } \\
\text { back skin }\end{array}$ & & \\
\hline Grape/seeds & $\begin{array}{c}\text { Cream: } \\
\text { Mineral oil }(16.07 \%), \text { span } 80 \\
(3.93 \%) \text {, Tween } 80(3.07), \\
\text { triethanolamine }(0.4 \%), \text { Carbopol } \\
940(0.5 \%), \text { glycerin }(5 \%), \\
\text { propylparaben }(1 \%), \text { q.s. water to } \\
100 \% \text {, grape seeds extract }(3 \%) *\end{array}$ & $\begin{array}{l}\text { Evaluation for texture } \\
\text { profiles, viscosity and } \\
\text { pH: at } 25^{\circ} \mathrm{C} \& 4{ }^{\circ} \mathrm{C} \\
\text { before and after heat cool } \\
\text { cycling ( } 6 \text { cycles) for } 12 \mathrm{~h}\end{array}$ & $\begin{array}{l}\text { SPF and PA } \\
\text { measurement }\end{array}$ & - & $\begin{array}{l}\text { UV protection booster: } \\
\text { SPF } 1.29 \\
\text { PA } 1.19\end{array}$ & {$[42]$} \\
\hline
\end{tabular}


Table 3. Cont

\begin{tabular}{|c|c|c|c|c|c|c|}
\hline \multirow{2}{*}{ Grape Variety/Fruit Part } & \multirow{2}{*}{ Product } & \multicolumn{3}{|c|}{ Product Evaluation } & \multirow{2}{*}{ Effect } & \multirow{2}{*}{ Ref } \\
\hline & & Stability & In Vitro & In Vivo & & \\
\hline Grape/seeds & $\begin{array}{c}\text { Lotion: } \\
\text { Anisotriazine }(8 \%) \text {, titanium } \\
\text { dioxide }(12 \%) \text {, silicone DC } 5562 \\
(5 \%) \text {, sorbitan monostearate }(1 \%) \text {, } \\
\text { cremophore A6 }(2 \%) \text {, cremophore } \\
\text { A25 }(1.5 \%) \text {, cetyl alcohol }(0.8 \%), \\
\text { beeswax }(0.8 \%) \text {, isopropyl } \\
\text { myristate }(2.4 \%) \text {, disodium EDTA } \\
(0.2 \%), \text { glycerin }(1 \%) \text {, propylene } \\
\text { glycol }(2 \%), \text { methyl paraben } \\
(0.1 \%), \text { propyl paraben }(0.02 \%), \\
\text { polysorbate } 60(1 \%) \text {, q.s. to water } \\
100 \% \text {, grape seeds extract }(1 \%) *\end{array}$ & $\begin{array}{l}\text { Evaluation for the } \\
\text { physical characteristic of } \\
\text { pH and viscosity after } \\
\text { freeze-thaw condition }(4 \\
\left.{ }^{\circ} \mathrm{C}, 45^{\circ} \mathrm{C}, 24 \mathrm{~h}\right) \text { for each } \\
\text { condition }(6 \text { cycles) }\end{array}$ & $\begin{array}{l}\text { SPF measurements } \\
\text { DPPH assay }\end{array}$ & - & $\begin{array}{c}\text { SPF booster up to } 53.58 \\
\text { Antioxidant activity }(84.04 \%)\end{array}$ & {$[50]$} \\
\hline Grape/seeds & $\begin{array}{c}\text { Cream: } \\
\text { ABIL-EM } 90 \text { (cetyl dimethicone } \\
\text { copolyol), paraffin oil, distilled } \\
\text { water, grape seeds extract } \\
(3 \%), \text { methyl paraben, glycerin, } \\
\text { lemon oil, } \\
\text { triethanolamine solution }\end{array}$ & $\begin{array}{c}\text { Evaluation at } 8{ }^{\circ} \mathrm{C}, 25^{\circ} \mathrm{C} \\
40^{\circ} \mathrm{C} \text { for } 12 \text { weeks for } \\
\text { stability, color and } \mathrm{pH}\end{array}$ & - & $\begin{array}{l}\text { Study of the moisture } \\
\text { content, } \mathrm{pH} \text { value, sebum } \\
\text { content, elasticity and } \\
\text { average pore size of skin } \\
\text { Questionnaire subjective } \\
\text { evaluation } \\
20 \text { females } \\
12 \text { weeks } \\
\text { Application on cheeks }\end{array}$ & $\begin{array}{c}\text { Stable product } \\
\text { Antiaging effects: } \\
\text { Reduction of size pores } \\
(56.8 \%) \\
\text { Reduction in roughness } \\
(18.98 \%) \\
\text { Increase in skin elasticity } \\
(47.95 \%) \\
\text { Increase in sebum content } \\
(93.85 \%) \\
\text { Increase in hydration }(47.56 \%) .\end{array}$ & {$[51]$} \\
\hline Vitisvinifera/seed & $\begin{array}{c}\text { Cream: } \\
\text { Paraffin oil (16\%), abil-EM 90 } \\
\text { (4\%), distilled water q.s. to } 100 \% \text {, } \\
\text { grape seeds extract (4\%), rose oil } \\
\text { ( } 2 \text { to } 3 \text { drops) }\end{array}$ & $\begin{array}{l}\text { Evaluation at } 8^{\circ} \mathrm{C}, \\
25^{\circ} \mathrm{C}, 40^{\circ} \mathrm{C} \text { for } 12 \text { weeks } \\
\text { for } \mathrm{pH} \text {, centrifugation, } \\
\text { electrical conductivity, } \\
\text { phase separation, } \\
\text { organoleptic and } \\
\text { physical characteristics }\end{array}$ & - & $\begin{array}{c}\text { Study of skin microrelief } \\
\text { parameters, elasticity, } \\
\text { moisture contents and } \\
\text { melanin } \\
11 \text { males } \\
12 \text { weeks } \\
\text { Application on cheeks }\end{array}$ & $\begin{array}{c}\text { Stable product } \\
\text { Antiaging effects } \\
\text { Skin depigmenting effects }\end{array}$ & {$[43]$} \\
\hline
\end{tabular}


Table 3. Cont

\begin{tabular}{|c|c|c|c|c|c|c|}
\hline \multirow{2}{*}{ Grape Variety/Fruit Part } & \multirow{2}{*}{ Product } & \multicolumn{3}{|c|}{ Product Evaluation } & \multirow{2}{*}{ Effect } & \multirow{2}{*}{ Ref } \\
\hline & & Stability & In Vitro & In Vivo & & \\
\hline Vitis viniferaL./seeds & $\begin{array}{c}\text { Liquid gel-based serum: } \\
\text { Grape seeds extract phytosome } \\
(10 \%) \text {, carbopol ultrez } 30(0.5 \%), \\
\text { triethanolamine (TEA) }(0.4 \%), \\
\text { propylene glycol }(10 \%), \\
\text { methylparabene }(0.18), \\
\text { propylparaben }(0.02 \%), \text { sodium } \\
\text { metabisulfite }(0.075 \%), \\
\text { demineralized water q.s. to } 100 \% \text { * }\end{array}$ & $\begin{array}{c}\text { Physicochemical } \\
\text { evaluations: } \\
\text { Organoleptic test (color, } \\
\text { odor, syneresis), } \\
\text { homogeneity, } \mathrm{pH}, \\
\text { viscosity and rheology }\end{array}$ & Penetration test $(18 \mathrm{~h})$ & - & $\begin{array}{l}\text { Increasing the penetration of } \\
\text { the phytosome into membrane }\end{array}$ & {$[52]$} \\
\hline Muscat Hamburg/seeds & $\begin{array}{c}\text { Cream: } \\
\text { Liquid paraffin }(16 \%) \text {, abil EM } 90 \\
(4 \%) \text {, grape seed extract }(2 \%), \\
\text { distilled water }(98 \%)\end{array}$ & - & - & $\begin{array}{l}\text { Patch test } \\
\text { Study the effects of the } \\
\text { formulations (containing or } \\
\text { not the extract) on melanin } \\
\text { content, erythema, } \\
\text { moisture, elasticity } \\
\text { and sebum } \\
110 \text { Males } \\
8 \text { weeks } \\
\text { Application on cheeks }\end{array}$ & $\begin{array}{l}\text { Absence of skin sensitive cases } \\
\text { Safe application } \\
\text { Decrease of skin melanin } \\
\text { content }(\sim 18 \%) \\
\text { Increase in skin elasticity } \\
(\sim 13 \%) \\
\text { Decrease in skin sebum } \\
\text { content }(15 \%) \\
\text { Increase skin moisture (data } \\
\text { not indicated) }\end{array}$ & [53] \\
\hline
\end{tabular}




\section{Potential In Vitro Cosmetic Applications of Grape Pomace Extracts}

The first step towards the assessment of an extract to be hypothetically used in cosmetic applications as an active ingredient is to conduct some in vitro tests. Those are a quick and cost-effective way to evaluate the potential use of grape pomace extracts in a specific biological activity prior to their incorporation in cosmetic formulas and the testing of their in vivo effectiveness in clinical trials. Grape pomace polyphenol extracts mainly exhibited promising antioxidant, antiaging, anti-hyperpigmentation and UV-protecting activities with in vitro testing (Table 2).

\subsection{Antioxidant Activity}

Antioxidants are valuable compounds that interrupt radical chains and protect cells from the damage caused by reactive species [54]. Among others, polyphenols are potent antioxidants capable of protecting human cells and tissues from oxidative stress [55]. Their presence in grape pomace extracts confers them a great antioxidant activity, as previously reported by several authors [22,37,38,42,46,47,49,56,57]. Vitis labrusca L. pomace [47], grape stems [56], Tempranillo red grape pomace [37], grape pomace [57], Carignano pomaces skins [38] and red grape seeds and stalks extracts [22] have all been tested to be used as an active ingredient in cosmetic formulations due to their antioxidant activity.

The antioxidant capacity of the grape seeds extract was evaluated in comparison to vitamin E acetate, Trolox and BHT using a DPPH assay. Natural grape seed extract only showed a better antioxidant activity than BHT. Its ability to scavenge free radicals ( $\mathrm{IC}_{50}$ $33.17 \mu \mathrm{g} / \mathrm{mL}$ ) was 6.23-fold lower than the synthetic molecule ( $\mathrm{IC}_{50} 206.81 \mu \mathrm{g} / \mathrm{mL}$ ) [42]. Likewise, Maluf et al. detected significant antioxidant effect $\left(\mathrm{EC}_{50} 6.9 \mu \mathrm{g} / \mathrm{mL}\right)$ of the Vitis labrusca $\mathrm{L}$. pomace extract, suggesting it as a natural alternative for the synthetic antioxidant ingredient $\mathrm{BHT}\left(\mathrm{EC}_{50} 7.6 \mathrm{\mu g} / \mathrm{mL}\right)$. This antioxidant activity was attributed to ellagic acid that was identified by HPLC [47].

On another note, the antioxidant activity of untreated red grape pomace extract was higher than the one obtained after a microwave irradiation pre-treatment $\left(80^{\circ} \mathrm{C}\right.$ for $\left.60 \mathrm{~s}\right)$. The same tendency was observed with three different chemical assays: ORAC (481 and $448 \mu \mathrm{mol} \mathrm{TE} / \mathrm{g}$ Extract), HOSC (746 and $441 \mu \mathrm{mol} \mathrm{TE} / \mathrm{g}$ Extract) and HORAC (305 and $198 \mu \mathrm{mol} \mathrm{CAE} / \mathrm{g}$ Extract). The results of the chemical assays were in accordance with the total phenolic (TPC), and the total anthocyanin (TAC) contents. In fact, TPC was 1.82-fold higher in the untreated extract than that of the pre-treated one, but the TAC was 1.58-fold higher in the treated extract compared to the untreated one, indicating that the microwaves irradiation selectively enhanced anthocyanin extraction leading to an antioxidant activity of this class only and not the other phenolic subclasses. Moreover, the cellular antioxidant activity of MW-treated and -untreated extracts was conducted on two cell lines: keratinocytes and fibroblasts. In concordance with the previous results, the unirradiated extract had better cellular protective effects against induced oxidative damage compared to the MW irradiated extract in both keratinocyte and fibroblast cell models respectively. In conclusion, it is important to validate the antioxidant cellular activity of the chemical assays in cellular cultures and biological environment to be able to better assess and confirm the results [37].

The antioxidant capacity of the grape pomace extracts was also shown to be dependent of the carrier system. Red grape seeds and stalks extracts $(40 \mu \mathrm{g} / \mathrm{mL})$ showed a higher antioxidant activity (reduction $88 \%$ of DPPH radicals) when incorporated into vesicles (liposomes, transferosomes, hyalurosomes, hyalo-transferosomes) compared to extracts in dispersion (reduction $78 \%$ of DPPH radicals) [22]. The extracts $(2 \mu \mathrm{g} / \mathrm{mL})$ loaded into these vesicles also provided protection from the $\mathrm{H}_{2} \mathrm{O}_{2}$-induced oxidative effect on the keratinocytes and fibroblasts in cell culture. Results showed an increased cell viability of both cell lines by up to $100 \%$ with extract loaded vesicles, compared to $88 \%$ and $92 \%$ of viability increase of keratinocytes and fibroblasts, respectively, when the extract is in dispersion [22]. Likewise, Perra et al. reported that the extract-loaded vesicles can enhance 
the cellular protection effects against hydrogen peroxide by up to $83 \%$ compared to $70 \%$ when the extract is in an aqueous dispersion [38].

Furthermore, the cytoprotective effect of the extracts was reported [22,37,38,47]. For example, Maluf et al. demonstrated that the lyophilized Vitis labrusca L. pomace extract studied at the lowest concentration $\left(0.73 \mathrm{mg} \cdot \mathrm{mL}^{-1}\right)$ was capable of effectively protecting fibroblasts from the damages caused by the treatment with $\mathrm{H}_{2} \mathrm{O}_{2}(600 \mu \mathrm{M})$ [47]. On that note, Tempranillo red grape pomace extracts $\left(0.25 \mathrm{mg} \cdot \mathrm{mL}^{-1}\right)$ also revealed their protective effects on both keratinocytes and fibroblasts that were co-incubated with a stressor, tertbutyl hydroperoxide (TBHP) [37].

\subsection{Anti-Hyperpigmentation Activity}

The pigmentation of the skin is associated with the accumulation and the production of melanin that is synthetized by tyrosinase enzyme. It is well known that phenolic compounds have structural analogies with the substrate of that enzyme and can thus inhibit melanin production (Figure 4) [37].

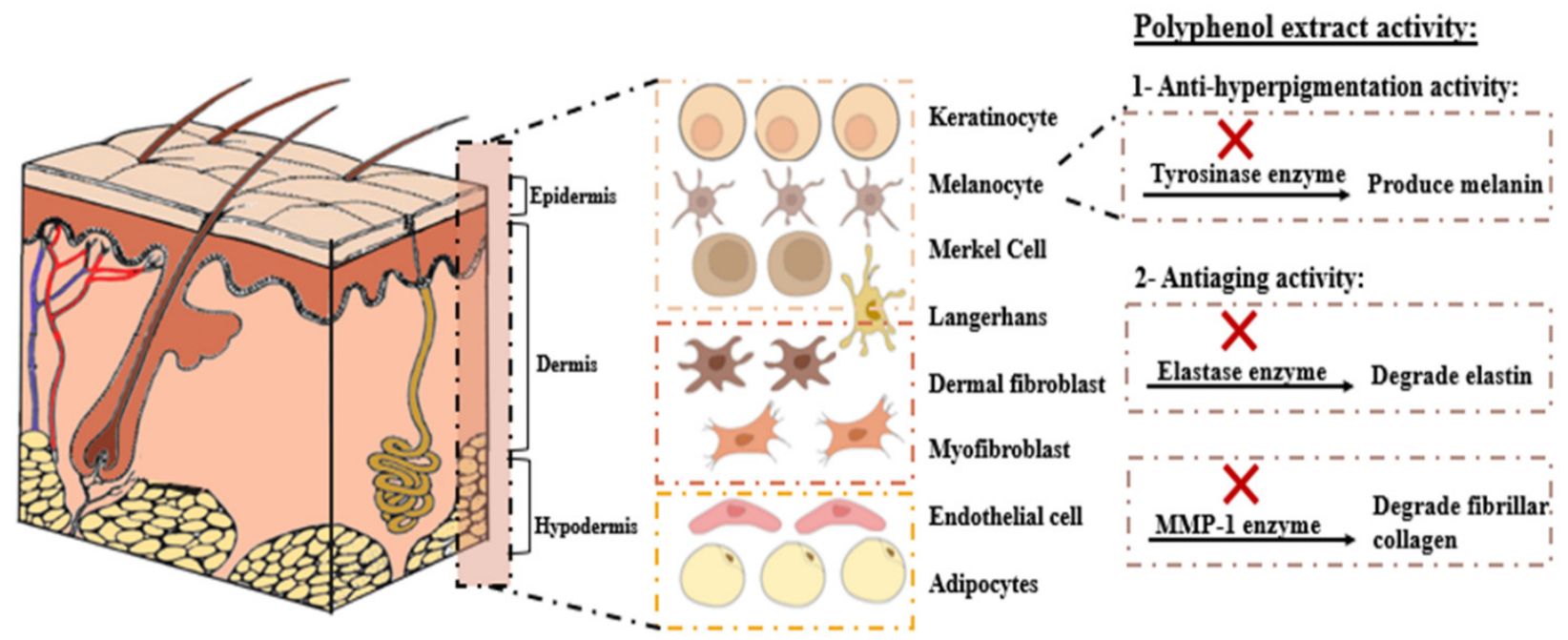

Figure 4. Effects of phenolic extracts on the skin anti-hyperpigmentation activity by inhibting tyrosinase enzyme as well as on the antiaging property by inhibting elastase and MMP-1 enzymes.

Red and white grape by-products have been studied for their inhibitory activities of tyrosinase enzyme. Results are likely to show the potential cosmetic application of polyphenols as active ingredient against hyperpigmentation $[37,40,44,46]$.

Matos et al. detected the in vitro inhibitory capacity of the tyrosinase enzyme by treating cells with Tempranillo red grape pomace extracts. Almost the same $\mathrm{IC}_{50}$ of $4.00 \mathrm{mg} / \mathrm{mL}$ was found for the untreated and the MW pre-treated samples. Although both extracts showed the same inhibiting capacity for the tyrosinase enzyme, the untreated extract had 2 times more TPC ( $83.9 \mathrm{mg}$ GAE/g extract) than the MW pre-treated one ( $45.9 \mathrm{mg}$ GAE/g extract). However, the MW pre-treated extract had 1.5 times more TAC (2.7 mg malv-3-O-gl/g Extract) than the untreated extract (1.7 mg malv-3-O-gl/g Extract). Moreover, HPLC analysis showed that the flavonols content was higher in the MW pre-treated extract than the untreated one. This means that the tyrosinase inhibiting activity does not depend only on the phenolic compounds' quantity but also their overall quality and diversity [37].

Ferri et al. used solvent based extraction process in $\mathrm{H}_{2} \mathrm{O}(100 \%)$ and $\mathrm{EtOH}: \mathrm{H}_{2} \mathrm{O}$ $(95: 5 \mathrm{v} / \mathrm{v})$ for the mixture of white grapes (Trebbiano and Verdicchio) pomaces. The hydroethanolic solvent was 1.5 times more efficient than water in terms of polyphenol quantity. Moreover, the drying pre-treatment of pomaces was shown to enhance by 2.1-fold the recovery of polyphenols and by 2.8 -folds the anti-tyrosinase activity (686.3 $\mathrm{mg} \mathrm{KA} \mathrm{eq/L)}$ compared to the wet pomace (243.3 $\mathrm{mg} \mathrm{KA} \mathrm{eq/L)} \mathrm{[44].}$ 
Leal et al. compared the antioxidant and anti-tyrosinase activities of red (Tinta Roriz, Touriga Nacional, Castelão, Syrah) and white grape stems (Arinto and Fernão Pires) by means of DPPH, ABTS and FRAP assays. Touriga Nacional variety had the highest antioxidant activities among the white and red grape stems with values of 0.64 Trolox per gram of dry weight (T/g dw), $0.84 \mathrm{~T} / \mathrm{g} \mathrm{dw}$ and $1.03 \mathrm{~T} / \mathrm{g} \mathrm{dw}$ respectively. As for the white varieties, Ferno Pires had the highest antioxidant activity for the three assays $(0.55 \mathrm{~T} / \mathrm{g} \mathrm{dw}$, $0.69 \mathrm{~T} / \mathrm{g} \mathrm{dw}$ and $0.99 \mathrm{~T} / \mathrm{g} \mathrm{dw}$ respectively). As for the anti-tyrosinase activity, the white and red grape stem extracts $(1 \mathrm{mg} / \mathrm{mL})$ inhibited the tyrosinase enzyme from $41.47 \%$ to $53.83 \%$. The Syrah variety exhibited the highest activity making it more suitable as a raw material for recovering polyphenols with high anti-tyrosinase activity [46].

Michailidis et al. demonstrated that, on the one hand, ultrasound grape seed paste extracts $(500 \mu \mathrm{g} / \mathrm{mL})$, obtained using EtOH solvent or EtOH: $\mathrm{H}_{2} \mathrm{O}(1: 1 v / v)$ mixture, showed higher anti-tyrosinase activity (75\% and $72.4 \%$, respectively) than the kojic acid positive control $(7.1 \mu \mathrm{g} / \mathrm{mL}, 52 \%)$. On the other hand, the extracts obtained by supercritical fluid extraction (using 10\% and $20 \% \mathrm{EtOH} w / w)$ showed lower anti-tyrosinase activity $(\approx 15 \%)$ than the positive control (kojic acid $7.1 \mu \mathrm{g} / \mathrm{mL}, 52 \%$ ). The difference in the anti-tyrosinase activity between both extraction techniques is attributed to the higher proanthocyanidin derivates content detected in the ultrasound extracts compared to the supercritical fluid extracts [40]. The anti-tyrosinase inhibitory properties of the grape pomace extracts made the latter a potential anti-hyperpigmentation agent.

\subsection{Antiaging Activity}

Elastase, collagenase and matrix metalloproteinase-1 (MMP-1) are enzymes associated with skin aging. The elastase and collagenase enzymes are involved in degrading collagen and elastin responsible to providing the skin with strength and elasticity, while MMP-1 causes the degradation of fibrillar collagen in the skin (Figure 4) [37,40].

White and red grape by-products extracts have been studied for their effectiveness as antiaging agents $[37,40,46,58]$. Matos et al. reported that the Tempranillo red pomace extracts can inhibit the activity of both enzymes in vitro: elastase ( $\mathrm{IC}_{50} 0.87 \mathrm{mg} / \mathrm{mL}$ ) and MMP-1 ( $\mathrm{IC}_{50} 1.08 \mathrm{mg} / \mathrm{mL}$ ) suggesting it as a bioactive with a key role for antiaging in cosmetics [37]. From that perspective, Leal et al. reported that white (Arinto and Fernão Pires) and red (Tinta Roriz, Touriga Nacional, Castelão, Syrah) grape stems (1 mg/mL) inhibited the elastase enzyme in a range from $67.98 \%$ to $98.02 \%$. In concordance with the anti-tyrosinase activity, Syrah variety showed the highest inhibition activity against elastase enzyme (98.02\%) [46].

Concerning the anti-elastase enzyme activity, Michailidis et al. reported that the ultrasound grape seeds paste extract $(300 \mu \mathrm{g} / \mathrm{mL})$ using EtOH solvent and EtOH: $\mathrm{H}_{2} \mathrm{O}$ $(1: 1 v / v)$ mixture, have higher inhibitory effects $(91.3 \%$ and $83.2 \%)$ than the positive control, Elastatinal $(0.5 \mu \mathrm{g} / \mathrm{mL}, 51.3 \%)$. In concordance with the results showed for antityrosinase activity, the supercritical extracts (using 10\% and 20\% $\mathrm{EtOH} w / w$ ) had lower anti-elastase activity $(\approx 35 \%$ ) than the positive control (Elastatinal $0.5 \mu \mathrm{g} / \mathrm{mL}, 51.3 \%$ ). As for the anti-collagenase enzyme activity, the ultrasound extracts $(600$ and $200 \mu \mathrm{g} / \mathrm{mL}) \mathrm{using}$ EtOH solvent and EtOH: $\mathrm{H}_{2} \mathrm{O}(1: 1 \mathrm{v} / \mathrm{v})$ mixture reached around $100 \%$ of inhibition. The supercritical extract $(600 \mu \mathrm{g} / \mathrm{mL}$ ) (using 10\% and 20\% EtOH $w / w$ ) was also higher (up to $80 \%$ and $90 \%)$ than the positive control, Phosphoramidon (16 $\mu \mathrm{M}, 46.4 \%)$ [40]. Moreover, Weisser Riesling grape pomace were also shown to have inhibitory effects for both enzymes: collagenase and elastase. The highest polyphenol value evaluated $(35.3 \mu \mathrm{g} / \mathrm{mL})$ lead to inhibit $80 \%$ and $73 \%$ respectively of collagenase and elastase [58].

The results suggested the use of grape pomace extract as antiaging agent due to its inhibitory effects of the elastase, collagenase and matrix metalloproteinase- 1 enzymes.

Many other aspects were also evaluated on the grape extracts such as the photoprotection capacity [41,42] and the cytotoxicity effects [41,47]. 


\section{Incorporation of the Grape By-Products Extracts in Cosmetic Products and Their In Vitro and/or In Vivo Testing}

Following the favorable in vitro tests conducted on grape extracts, the latter was incorporated in different cosmetic products such as creams [41-43,45,51], lotions [50], toothpastes [39] and serums [52] to test their stability and their in vitro and/or in vivo effectiveness. Table 3 studies the stability $[42,43,45,50-52]$, in vitro $[39,41,42,45,49,50]$ and in vivo $[39,43,45,51]$ evaluation of the incorporation of the grape pomace extracts in cosmetic products. The grape by-product (pomace, skin, seeds) extract was incorporated in the final products in a range varying from $1 \%$ to $10 \%$, in freeze-dried form [45], or in liquid form [41-43].

\subsection{Sunscreen Application}

Grape by-products' extracts were studied for their potential use as bioactive ingredients for UV protection [41,42,45,49], whether deriving from pomaces [45] or seeds [41,42,49]. Cabernet Sauvignon pomace extract was obtained using percolation with a hydro-ethanolic mixture $(70: 30 v / v)$ [45], while grape seed extracts were whether commercially bought [50] or recovered by maceration ( 1 week, $95 \%$ ethanolic solvent) [41,42].

Extracts were incorporated in creams in different percentages ranging from $1 \%$ $1.46 \%, 3 \%$ or $5 \%[41,42,45,49]$ to $8.54 \%$ or $10 \%$ [45], being combined or not with UV filters ingredients.

For example, Hübner et al. developed, using the factorial design, several formulations by varying the UV filters concentration, the extract concentration, and the irradiation time. The most stable formulations exhibiting high antioxidant activities were selected for the clinical in vivo analyses. Therefore, the mixture of the Cabernet Sauvignon pomace extract $(10 \%)$ and the UV filters (butylmethoxydibenzoyl methane $2.5 \%$, ethylhexyl methoxycinnamate 5\% and ethylhexyl dimethyl PABA 4\%) were selected and studied in an oil-in-water emulsion and compared to a formula that contains only the same UV filters without the extract. The effectiveness of this product (extract + UV filters) was confirmed by the highest obtained antioxidant activity $\left(519.92 \mu \mathrm{mol} \cdot \mathrm{g}^{-1}\right)$. The synergy of the extract and the UV filters provided higher in vitro and in vivo SPF values (16.33 and 12.30, respectively) compared to the other formulation when the chemical UV filters were alone ( 6.00 and 10.20 , respectively). A synergism between natural grape pomace extracts and synthetic UV filters is suggested to provide photoprotection effects. Grape pomace extract has antioxidant activity and can be safely applied in sunscreens [45].

In concordance with these findings, Yarovaya et al. reported the effectiveness of combining grape seeds extracts (3\%) with UV filter octyl methoxycinnamate (OMC, 7\%) in a sunscreen formulation. The extract $(25 \mu \mathrm{g} / \mathrm{mL})$ was evaluated in vitro prior to its incorporation in the cosmetic product. It showed to significantly increase the fibroblasts viability up to $68 \%$ and protect the cells from the UVA damages by means of the MTT assay. The extract was capable of restoring the original morphology of the UVA irradiated cells up to $46 \%$ compared to the untreated cells. Subsequently, the sunscreen cream was formulated and the synergy between OMC $(7 \%)$ and the extract was proven. The photodegradation of catechins was reduced to $\approx 4.6 \%$ and that of epicatechins to $\approx 7.0 \%$, showing a photostability of the molecules [41].

Moreover, Khunkitti confirmed the in vitro photoprotective effect of grape seed extracts when added at $3 \%$ in base cream formula. The results showed that the extract enhanced the sunscreen protection effect by increasing the SPF value from 18.22 to 23 in the product [42].

Limsuwan and Amnuikit also confirmed the high photoprotection capacity of the lotion when combining grape seed extracts, even at a $1 \%$ concentration, with UV filters ( $8 \%$ anisotriazine and $12 \%$ titanium dioxide). Indeed, the SPF value increased from 45.17 to 53.58 after the incorporation of the extract (1\%) in the sunscreen lotion [50].

Therefore, grape seed and pomace extracts are suggested to be added from $1 \%$ to $10 \%$ in sunscreen products to enhance the photoprotection effects. 


\subsection{Skin Penetration}

Many efforts were made aiming to improve the penetration of the plant-derived phenolic compounds into and through the skin. Accordingly, many phytosome formulas containing grape seed extracts were prepared and characterized in terms of morphology, zeta potential, size distribution and entrapment efficiency. The selected phytosome contained a 1:1 mass ratio of grape seeds extracts and Phospholipon $90 \mathrm{G}$. It was spherical with a zeta potential of $-25.2 \mathrm{mV}$, a $\mathrm{D}_{\text {mean }}$ volume of $398.23 \mathrm{~nm}$, and an entrapment efficiency of $75.01 \pm 0.25 \%$. A gel-based serum was then formulated containing $10 \%$ of grape seed extract phytosomes and tested in an in vitro penetration study. The phytosomal serum promoted the penetration of the bioactive total phenolic into the skin by $27.25 \%$ compared to $11 \%$ for the non-phytosomal serum [52].

\subsection{Antiaging and Skin Depigmenting Activities}

It is important to validate the in vitro antiaging (anti-elastase, anti-collagenase and anti-matrix metalloproteinase- 1 activities) and skin depigmenting effects (anti-tyrosinase activity), by studying the in vivo results to validate the claims of the grape by-products extracts.

Grape seeds extract was clinically evaluated over 12 weeks for its antiaging effects $[43,49,51,53]$. The extract was incorporated at $2 \%$ [53], 3\% [51], 4\% [43] and 5\% [49] in a cosmetic product and its efficacy was evaluated by means of biophysical parameters.

Rafique and Hussain Shah studied the antiaging activity of the cream containing $3 \%$ of the dried grape seed extract in comparison with the control formulation. The stability of the product was confirmed in vitro. The clinical study ( 20 females, 12 weeks) was evaluated using biophysical measurements. It resulted in a remarkable reduction of pore size (56.8\%) and roughness (18.98\%), along with enhancement in skin elasticity (47.95\%), sebum content $(93.85 \%)$ and hydration $(47.56 \%)$. The results were in accordance with the score of the questionnaire answered by the volunteers [51].

Grape seed extract was incorporated at $2 \%$ in a water-in-oil emulsion. The clinical effects of the stable product were evaluated in vivo and were compared to the control formulation. The study (110, 8 weeks) was realized by using non-invasive instruments. The application of the cream containing the extract showed to be safe. It showed to have skin depigmenting activity by reducing the melanin content $(\sim 18 \%)$, and skin moisturizer activity on the cheeks of the volunteers. Moreover, it showed promising antiaging effects by increasing the skin elasticity $(\sim 13 \%)$. The product containing the extract also showed to decrease the skin sebum content $(\sim 15 \%)$ [53].

In another study, the organic phase of the grape seeds extract was evaporated after the extraction in EtOH: $\mathrm{H}_{2} \mathrm{O}(95: 5 \mathrm{v} / \mathrm{v})$ for 7 days. The extract was rich in phenolic compounds (catechin, epicatechin, gallic acid, epicatechin gallate, and procyanidin dimers (B-1, B-2 and B-3)) as determined by HPLC. The liquid extract was added in $5 \%$ to an emulsion and to an emulgel product. Then the formulations were physically characterized and their rheological parameters were studied. After confirming the stability and the safety of the products, clinical trials on 40 females for 12 weeks were conducted to test the antiaging claims. Results highlighted the reduction in roughness (14\% and 55\%), scaliness (13\% and $26 \%$ ), wrinkles ( $21 \%$ and $23.9 \%$ ) and sebum content $(26.13 \%$ and $30.3 \%)$, for the emulsion and the emulgel respectively. Furthermore, the increase of elasticity $(45.3 \%$ and $50 \%)$ and hydration (29.85\% and $32.2 \%$ ) was highlighted. The emulgel presented overall better antiaging results than the emulsion due to its better-controlled release effect. The hydrating, anti-inflammatory and anti-wrinkle effects are associated with the presence of phenolic compounds in the grape seed extract [49].

Waqas et al. obtained concentrated grape seeds extract after the evaporation of the organic solvent from the $\mathrm{MeOH}: \mathrm{H}_{2} \mathrm{O}(70: 30 \mathrm{v} / \mathrm{v})$ blend used during maceration $(72 \mathrm{~h})$. The remaining aqueous extract was incorporated at a $4 \%$ concentration in a cosmetic emulsion. After confirming the stability of the cream $(\mathrm{pH}$, color, electrical conductivity etc.), and its non-irritability, it was tested in clinical trials on 11 males for 12 weeks. The results underlined the regular increase of the elasticity and moisture of the skin and the 
effective reduction of the wrinkles. Moreover, skin depigmenting effects were associated to the reduction of melanin content. The amelioration of the skin status is attributed to the presence of phenolic compounds and flavonoids in the extracts [43].

Therefore phenolic compounds contained in grape by-products are suggested to be beneficial ingredients for the production of cosmetics with antiaging and skin depigmenting properties $[43,51]$.

\subsection{Oral Care Application}

Phenolic compounds extracts from grape by-products were suggested as oral care products and were especially studied in toothpastes [39].

Emmulo at al. evaluated the effect of several extraction parameters such as red or white grapes, skins or seeds; water or ethanol; ultrasounds, etc., on polyphenol recovery. The latter was then freeze-dried and added at different percentages (2-10\%) to commercial toothpastes. The hydroethanolic $(60: 30 \mathrm{v} / \mathrm{v})$ white Grechetto seeds extracts are almost 2 times richer in total polyphenol content than the skin. Moreover, HPLC results showed that ethanolic solvent recovered 2 times more quercetin $(\approx 20.6 \mathrm{mg} / \mathrm{L})$ than water extract $(\approx 10.4 \mathrm{mg} / \mathrm{L})$ and that ultrasounds did not intensify $(\approx 19.7 \mathrm{mg} / \mathrm{L})$ its extraction in ethanol.

The water or hydroethanolic extracts were then freeze-dried and added into commercial toothpaste at concentrations of $5 \%$ or $10 \%$, and of $2.5 \%$ or $5 \%$, respectively. The addition of white grape seeds and skins as well as red grape seed pomace extracts increased the polyphenol content in commercial toothpastes.

The stability and shelf-life study confirmed that the toothpaste enriched with aqueous extracts $(5 \%$ and $10 \%)$ showed a persistent loss in polyphenol content $(3.9$ and $9.4 \%$, respectively) after 4 months. On the other hand, toothpastes enriched with whereas ethanol extracts were stable. The in vitro studies showed that the toothpaste with $10 \%$ aqueous seeds extract showed the highest antiradical activity, after 4 months. However, the toothpaste with only $5 \%$ of seeds extract obtained by aqueous extraction was the most appreciated among the consumers. This was associated with the lower content in proanthocyanidins compared to the other samples, affecting the astringency of the toothpaste [39].

\section{Conclusions}

Grape pomace extracts have big potential to be used as key components for the formulation of innovative cosmetic products due to their high content in bioactive molecules and polyphenols. The latter have several health benefits at skin level, such as antiaging, skin depigmenting and photo protection. Grape seed and skin extracts were also reported as antioxidants for the formulation of oral care products.

The recovery of highly bioactive compounds is conducted using classical or innovative methods. However, the traditional hydroethanolic solid liquid extraction technique is still the most widely used. The main bioactive compounds detected in grape pomaces were gallic acid, catechin, epicatechin, epicatechin gallate, and quercetin. The activities of the extracts were studied by referring to enzymatic, in vitro cellular culture assay and DPPH methods.

Many studies were published on the use of grape by-products in cosmetics and others need to be further developed to better understand the beneficial effect connected to the incorporation and formulation of polyphenol extracts into the cosmetic products. Moreover, more clinical trials on cosmetic products containing grape pomace extracts are needed to better evaluated and confirm the beneficial properties of these molecules on the human skin.

Finally, it is extremely important to master the extraction process that will allow to control the quantity and quality of the recovered polyphenols. The link between the extraction parameters, the recovered components and their influence on the stability of the cosmetic formulations needs to be further investigated. Finally, more research is 
needed to understand even more the link between the extraction techniques allowing the recovery of certain classes of polyphenols and the desirability of the cosmetic product by the end consumer.

Author Contributions: Original draft preparation, I.H. and H.N.R.; Writing, review and editing, I.H., and H.N.R.; Review and editing, R.E.K., S.Y., N.L., R.G.M., M.M. and M.L.M. All authors have read and agreed to the published version of the manuscript.

Funding: This review was funded by L'ORÉAL UNESCO FOR WOMEN IN SCIENCE LEVANT YOUNG TALENTS PROGRAM and by the European Union under the ENI CBC MED Programme 2014-2020, BESTMEDGRAPE Project reference number A_A.2.1_0035.

Institutional Review Board Statement: Not applicable.

Informed Consent Statement: Not applicable.

Data Availability Statement: Not applicable.

Acknowledgments: Authors would like to acknowledge Berytech's agrytech program with support from the Kingdom of the Netherlands for technical support and synergy.

Conflicts of Interest: The authors declare no conflict of interest.

\section{References}

1. El Kantar, S.; Rajha, H.N.; Maroun, R.G.; Louka, N. Intensification of polyphenols extraction from orange peels using infrared as a novel and energy saving pretreatment. J. Food Sci. 2020, 85, 414-420. [CrossRef]

2. El Kantar, S.; Boussetta, N.; Rajha, H.N.; Maroun, R.G.; Louka, N.; Vorobiev, E. High voltage electrical discharges combined with enzymatic hydrolysis for extraction of polyphenols and fermentable sugars from orange peels. Food Res. Int. 2018, 107, 755-762. [CrossRef]

3. El Kantar, S.; Boussetta, N.; Lebovka, N.; Foucart, F.; Rajha, H.N.; Maroun, R.G.; Louka, N.; Vorobiev, E. Pulsed electric field treatment of citrus fruits: Improvement of juice and polyphenols extraction. Innov. Food Sci. Emerg. Technol. 2018, 46, 153-161. [CrossRef]

4. $\quad$ El Kantar, S.; Rajha, H.N.; Boussetta, N.; Vorobiev, E.; Maroun, R.G.; Louka, N. Green extraction of polyphenols from grapefruit peels using high voltage electrical discharges, deep eutectic solvents and aqueous glycerol. Food Chem. 2019, 295, 165-171. [CrossRef] [PubMed]

5. Abi-Khattar, A.M.; Rajha, H.N.; Abdel-Massih, R.M.; Habchi, R.; Maroun, R.G.; Debs, E.; Louka, N. “Intensification of Vaporization by Decompression to the Vacuum" (IVDV), a novel technology applied as a pretreatment to improve polyphenols extraction from olive leaves. Food Chem. 2021, 342, 128236. [CrossRef] [PubMed]

6. Abi-Khattar, A.M.; Rajha, H.N.; Abdel-Massih, R.M.; Maroun, R.G.; Louka, N.; Debs, E. Intensification of polyphenol extraction from olive leaves using ired-irrad ${ }^{\circledR}$, an environmentally-friendly innovative technology. Antioxidants 2019, 8, 227. [CrossRef] [PubMed]

7. Abi-Khattar, A.M.; Rajha, H.N.; Maroun, R.G.; Abdel-Massih, R.M.; Louka, N.; Debs, E. Green extraction of polyphenols from olive leaves using ired-irrad ${ }^{\circledR}$ as a pretreatment. In Proceedings of the 5th International Conference on Renewable Energy in Developing Countries REDEC 2020, Marrakech, Morocco, 29-30 June 2020; pp. 1-5. [CrossRef]

8. Rajha, H.N.; Abi-Khattar, A.M.; El Kantar, S.; Boussetta, N.; Lebovka, N.; Maroun, R.G.; Louka, N.; Vorobiev, E. Comparison of aqueous extraction efficiency and biological activities of polyphenols from pomegranate peels assisted by infrared, ultrasound, pulsed electric fields and high-voltage electrical discharges. Innov. Food Sci. Emerg. Technol. 2019, 58, 102212. [CrossRef]

9. Rajha, H.N.; Mhanna, T.; El Kantar, S.; El Khoury, A.; Louka, N.; Maroun, R.G. Innovative process of polyphenol recovery from pomegranate peels by combining green deep eutectic solvents and a new infrared technology. LWT 2019, 111, 138-146. [CrossRef]

10. Rajha, H.N.; Koubaa, M.; Boussetta, N.; Maroun, R.G.; Louka, N.; Lebovka, N.; Vorobiev, E. Selective ultrasound-assisted aqueous extraction of polyphenols from pomegranate peels and seeds. J. Food Process. Preserv. 2020, 44, e14545. [CrossRef]

11. El Darra, N.; Rajha, H.N.; Debs, E.; Saleh, F.; El-Ghazzawi, I.; Louka, N.; Maroun, R.G. Comparative Study between Ethanolic and $\beta$-Cyclodextrin Assisted Extraction of Polyphenols from Peach Pomace. Int. J. Food Sci. 2018, 2018, 9491681. [CrossRef]

12. Rajha, H.N.; Boussetta, N.; Louka, N.; Maroun, R.G.; Vorobiev, E. Pulsed Electric Fields and High Voltage Electrical Discharge Assisted Extraction of Biocompounds from Vine Shoots. In Handbook of Electroporation; Springer: Cham, Switzerland, 2016; pp. 1-16; ISBN 9783319267791.

13. Rajha, H.N.; El Kantar, S.; Afif, C.; Boussetta, N.; Louka, N.; Maroun, R.G.; Vorobiev, E. Selective multistage extraction process of biomolecules from vine shoots by a combination of biological, chemical, and physical treatments. Comptes Rendus Chim. 2018, 21, 581-589. [CrossRef]

14. Rajha, H.N.; Boussetta, N.; Louka, N.; Maroun, R.G.; Vorobiev, E. Electrical, mechanical, and chemical effects of high-voltage electrical discharges on the polyphenol extraction from vine shoots. Innov. Food Sci. Emerg. Technol. 2015, 31, 60-66. [CrossRef] 
15. Rajha, H.N.; Boussetta, N.; Louka, N.; Maroun, R.G.; Vorobiev, E. Effect of alternative physical pretreatments (pulsed electric field, high voltage electrical discharges and ultrasound) on the dead-end ultrafiltration of vine-shoot extracts. Sep. Purif. Technol. 2015, 146, 243-251. [CrossRef]

16. Rajha, H.N.; Chacar, S.; Afif, C.; Vorobiev, E.; Louka, N.; Maroun, R.G. $\beta$-Cyclodextrin-Assisted Extraction of Polyphenols from Vine Shoot Cultivars. J. Agric. Food Chem. 2015, 63, 3387-3393. [CrossRef]

17. Rajha, H.N.; Boussetta, N.; Louka, N.; Maroun, R.G.; Vorobiev, E. A comparative study of physical pretreatments for the extraction of polyphenols and proteins from vine shoots. Food Res. Int. 2014, 65, 462-468. [CrossRef]

18. Rajha, H.N.; Ziegler, W.; Louka, N.; Hobaika, Z.; Vorobiev, E.; Boechzelt, H.G.; Maroun, R.G. Effect of the drying process on the intensification of phenolic compounds recovery from grape pomace using accelerated solvent extraction. Int. J. Mol. Sci. 2014, 15, 18640-18658. [CrossRef] [PubMed]

19. Rajha, H.N.; El Darra, N.; Hobaika, Z.; Boussetta, N.; Vorobiev, E.; Maroun, R.G.; Louka, N. Extraction of Total Phenolic Compounds, Flavonoids, Anthocyanins and Tannins from Grape Byproducts by Response Surface Methodology. Influence of Solid-Liquid Ratio, Particle Size, Time, Temperature and Solvent Mixtures on the Optimization Process. Food Nutr. Sci. 2014, 5, 397-409. [CrossRef]

20. Rajha, H.N.; Louka, N.; El Darra, N.; Hobaika, Z.; Boussetta, N.; Vorobiev, E.; Maroun, R.G. Multiple Response Optimization of High Temperature, Low Time Aqueous Extraction Process of Phenolic Compounds from Grape Byproducts. Food Nutr. Sci. 2014, 5, 351-360. [CrossRef]

21. Rajha, H.N.; El Darra, N.; Vorobiev, E.; Louka, N.; Maroun, R.G. An Environment Friendly, Low-Cost Extraction Process of Phenolic Compounds from Grape Byproducts. Optimization by Multi-Response Surface Methodology. Food Nutr. Sci. 2013, 4, 650-659. [CrossRef]

22. Manca, M.L.; Firoznezhad, M.; Caddeo, C.; Marongiu, F.; Escribano-Ferrer, E.; Sarais, G.; Peris, J.E.; Usach, I.; Zaru, M.; Manconi, M.; et al. Phytocomplexes extracted from grape seeds and stalks delivered in phospholipid vesicles tailored for the treatment of skin damages. Ind. Crops Prod. 2019, 128, 471-478. [CrossRef]

23. Spinei, M.; Oroian, M. The potential of grape pomace varieties as a dietary source of pectic substances. Foods $2021,10,867$. [CrossRef] [PubMed]

24. Nigam, P.S.N.; Pandey, A. (Eds.) Biotechnology for Agro-Industrial Residues Utilisation: Utilisation of Agro-Residues; Springer Science and Business Media: New York, NY, USA, 2009; pp. 293-296; ISBN 9781402099410.

25. Muhlack, R.A.; Potumarthi, R.; Jeffery, D.W. Sustainable wineries through waste valorisation: A review of grape marc utilisation for value-added products. Waste Manag. 2018, 72, 99-118. [CrossRef] [PubMed]

26. FAO-OIV Focus 2016 Table and Dried Grapes; FAO: Rome, Italy, 2016.

27. Lee, S.Y.; Kim, B.N.; Han, J.H.; Chang, S.T.; Choi, Y.W.; Kim, Y.H.; Min, J. Treatment of phenol-contaminated soil by Corynebacterium glutamicum and toxicity removal evaluation. J. Hazard. Mater. 2010, 182, 937-940. [CrossRef]

28. Soceanu, A.; Dobrinas, S.; Sirbu, A.; Manea, N.; Popescu, V. Economic aspects of waste recovery in the wine industry. A multidisciplinary approach. Sci. Total Environ. 2021, 759, 143543. [CrossRef]

29. Lin, D.; Xiao, M.; Zhao, J.; Li, Z.; Xing, B.; Li, X.; Kong, M.; Li, L.; Zhang, Q.; Liu, Y.; et al. An overview of plant phenolic compounds and their importance in human nutrition and management of type 2 diabetes. Molecules 2016, 21, 1374. [CrossRef]

30. Garrido, J.; Borges, F. Wine and grape polyphenols-A chemical perspective. Food Res. Int. 2013, 54, 1844-1858. [CrossRef]

31. Daayf, F.; El Hadrami, A.; El-Bebany, A.F.; Henriquez, M.A.; Yao, Z.; Derksen, H.; El-Hadrami, I.; Adam, L.R. Phenolic Compounds in Plant Defense and Pathogen Counter-Defense Mechanisms. In Recent Advances in Polyphenol Research; Wiley: Hoboken, NJ, USA, 2012; Volume 3, pp. 191-208; ISBN 9781444337464.

32. Nunes, M.A.; Rodrigues, F.; Oliveira, M.B.P.P. Grape Processing By-Products as Active Ingredients for Cosmetic Proposes. In Handbook of Grape Processing By-Products; Galanakis, C.M., Ed.; Elsevier Inc.: Amsterdam, The Netherlands, 2017; pp. 267-292; ISBN 9780128098714.

33. De Lima Cherubim, D.J.; Buzanello Martins, C.V.; Oliveira Fariña, L.; da Silva de Lucca, R.A. Polyphenols as natural antioxidants in cosmetics applications. J. Cosmet. Dermatol. 2020, 19, 33-37. [CrossRef]

34. Morocho-Jácome, A.L.; Freire, T.B.; de Oliveira, A.C.; de Almeida, T.S.; Rosado, C.; Velasco, M.V.R.; Baby, A.R. In vivo SPF from multifunctional sunscreen systems developed with natural compounds-A review. J. Cosmet. Dermatol. 2020, 20, 729-737. [CrossRef]

35. Richard, G.; Maroun, H.N.R.; Eugene Vorobiev, N.L. Emerging Technologies for the Recovery of Valuable Compounds From Grape Processing By-Products. In Handbook of Grape Processing By-Products; Galanakis, C.M., Ed.; Elsevier Inc.: Amsterdam, The Netherlands, 2017; pp. 155-181; ISBN 9780128098707.

36. Simonetti, G.; Brasili, E.; Pasqua, G. Antifungal Activity of Phenolic and Polyphenolic Compounds from Different Matrices of Vitis vinifera L. Against Human Pathogens. Molecules 2020, 25, 3748. [CrossRef]

37. Matos, M.S.; Romero-Díez, R.; Álvarez, A.; Bronze, M.R.; Rodríguez-Rojo, S.; Mato, R.B.; Cocero, M.J.; Matias, A.A. Polyphenolrich extracts obtained from winemaking waste streams as natural ingredients with cosmeceutical potential. Antioxidants 2019, 8, 355. [CrossRef]

38. Perra, M.; Lozano-Sánchez, J.; Leyva-Jiménez, F.J.; Segura-Carretero, A.; Pedraz, J.L.; Bacchetta, G.; Muntoni, A.; De Gioannis, G.; Manca, M.L.; Manconi, M. Extraction of the antioxidant phytocomplex from wine-making by-products and sustainable loading in phospholipid vesicles specifically tailored for skin protection. Biomed. Pharmacother. 2021, 142, 111959. [CrossRef] [PubMed] 
39. Emmulo, E.; Ceccantoni, B.; Bellincontro, A.; Mencarelli, F. Use of water and ethanol extracts from wine grape seed pomace to prepare an antioxidant toothpaste. J. Sci. Food Agric. 2021, 101, 5813-5818. [CrossRef]

40. Michailidis, D.; Angelis, A.; Nikolaou, P.E.; Mitakou, S.; Skaltsounis, A.L. Exploitation of vitis vinifera, foeniculum vulgare, cannabis sativa and punica granatum by-product seeds as dermo-cosmetic agents. Molecules 2021, 26, 731. [CrossRef] [PubMed]

41. Yarovaya, L.; Waranuch, N.; Wisuitiprot, W.; Khunkitti, W. Effect of grape seed extract on skin fibroblasts exposed to UVA light and its photostability in sunscreen formulation. J. Cosmet. Dermatol. 2020, 20, 1271-1282. [CrossRef] [PubMed]

42. Khunkitti, L.Y. and W. The Effect of Grape Seed Extract as a Sunscreen Booster. Songklanakarin J. Sci. Technol. 2019, 4, 708-715. [CrossRef]

43. Waqas, M.K.; Akhtar, N.; Rasul, A.; Sethi, A.; Abbas, K.; Hussain, T. Non-invasive in vivo evaluations of cosmetic emulsion containing phytoextract of grape seeds in the treatment of skin aging by using non-invasive bio-engineering techniques. Acta Pol. Pharm. Drug Res. 2018, 75, 97-105.

44. Ferri, M.; Rondini, G.; Calabretta, M.M.; Michelini, E.; Vallini, V.; Fava, F.; Roda, A.; Minnucci, G.; Tassoni, A. White grape pomace extracts, obtained by a sequential enzymatic plus ethanol-based extraction, exert antioxidant, anti-tyrosinase and anti-inflammatory activities. N. Biotechnol. 2017, 39, 51-58. [CrossRef]

45. Hübner, A.A.; Sarruf, F.D.; Oliveira, C.A.; Neto, A.V.; Fischer, D.C.H.; Kato, E.T.M.; LourençO, F.R.; Baby, A.R.; Bacchi, E.M. Safety and photoprotective efficacy of a sunscreen system based on grape pomace (Vitis vinifera L.) phenolics from winemaking. Pharmaceutics 2020, 12, 1148. [CrossRef]

46. Leal, C.; Gouvinhas, I.; Santos, R.A.; Rosa, E.; Silva, A.M.; Saavedra, M.J.; Barros, A.I.R.N.A. Potential application of grape (Vitis vinifera L.) stem extracts in the cosmetic and pharmaceutical industries: Valorization of a by-product. Ind. Crops Prod. 2020, 154, 112675. [CrossRef]

47. Maluf, D.F.; Gonçalves, M.M.; D’Angelo, R.W.O.; Girassol, A.B.; Tulio, A.P.; Pupo, Y.M.; Farago, P.V. Cytoprotection of antioxidant biocompounds from grape pomace: Further exfoliant phytoactive ingredients for cosmetic products. Cosmetics 2018, 5, 46. [CrossRef]

48. Panić, M.; Gunjević, V.; Radošević, K.; Bubalo, M.C.; Ganić, K.K.; Redovniković, I.R. Cosmotherm as an effective tool for selection of deep eutectic solvents based ready-to-use extracts from Graševina grape pomace. Molecules 2021, 26, 4722. [CrossRef] [PubMed]

49. Rafique, M.; Nisar, S.; Shah, H.; Hussain, I. Development of grape seed extract based formulations by using non-invasive biophysical technique and its impact on skin aging Development of grape seed extract based formulations by using non- invasive biophysical technique and its impact on skin aging. Pak. J. Pharm. Sci. 2021, 34, 1621-1628. [CrossRef]

50. Limsuwan, T.; Amnuikit, T. Effect of grape seed extract in sunscreen lotion on sun protection factor (SPF) determined by in vitro method. ACM Int. Conf. Proceeding Ser. 2017, F1309, 109-112. [CrossRef]

51. Rafique, M.; Hussain Shah, S.N. Anti-Ageing Potential of a Cream (W/O Emulsion) Containing Grape Seed Extract (GSE): Formulation and in vivo Evaluation of Effectiveness Using Non-Invasive Biophysical Technique. J. Clin. Exp. Dermatol. Res. 2019, 10, 2155-9554. [CrossRef]

52. Surini, S.; Mubarak, H.; Ramadon, D. Cosmetic serum containing grape (Vitis vinifera L.) seed extract phytosome: Formulation and in vitro penetration study. J. Young Pharm. 2018, 10, s51-s55. [CrossRef]

53. Sharif, A.; Akhtar, N.; Khan, M.S.; Menaa, A.; Menaa, B.; Khan, B.A.; Menaa, F. Formulation and evaluation on human skin of a water-in-oil emulsion containing Muscat hamburg black grape seed extract. Int. J. Cosmet. Sci. 2014, 37, 253-258. [CrossRef]

54. Soto, M.L.; Falqué, E.; Domínguez, H. Relevance of natural phenolics from grape and derivative products in the formulation of cosmetics. Cosmetics 2015, 2, 259-276. [CrossRef]

55. Caddeo, C.; Manca, M.L.; Peris, J.E.; Usach, I.; Diez-Sales, O.; Matos, M.; Fernàndez-Busquets, X.; Fadda, A.M.; Manconi, M. Tocopherol-loaded transfersomes: In vitro antioxidant activity and efficacy in skin regeneration. Int. J. Pharm. 2018, 551, 34-41. [CrossRef]

56. Anastasiadi, M.; Pratsinis, H.; Kletsas, D.; Skaltsounis, A.L.; Haroutounian, S.A. Grape stem extracts: Polyphenolic content and assessment of their in vitro antioxidant properties. LWT Food Sci. Technol. 2012, 48, 316-322. [CrossRef]

57. Franco, D.; Sineiro, J.; Rubilar, M.; Sánchez, M.; Jerez, M.; Pinelo, M.; Costoya, N.; Núñez, M.J. Polyphenols from plant materials: Extraction and antioxidant power. Electron. J. Environ. Agric. Food Chem. 2008, 7, 3210-3216.

58. Wittenauer, J.; MäcKle, S.; Sußmann, D.; Schweiggert-Weisz, U.; Carle, R. Inhibitory effects of polyphenols from grape pomace extract on collagenase and elastase activity. Fitoterapia 2015, 101, 179-187. [CrossRef] [PubMed] 